

\title{
Buoyancy-Driven Ventilation of Hydrogen From Buildings: Laboratory Test and Model Validation
}

\author{
C.D. Barley and K. Gawlik
}

Prepared under Task No. H274.7110

Technical Report NREL/TP-550-45804

May 2009

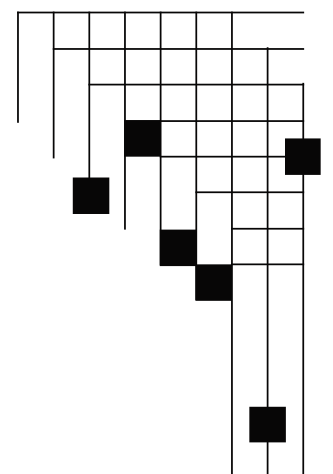




\section{NOTICE}

This report was prepared as an account of work sponsored by an agency of the United States government. Neither the United States government nor any agency thereof, nor any of their employees, makes any warranty, express or implied, or assumes any legal liability or responsibility for the accuracy, completeness, or usefulness of any information, apparatus, product, or process disclosed, or represents that its use would not infringe privately owned rights. Reference herein to any specific commercial product, process, or service by trade name, trademark, manufacturer, or otherwise does not necessarily constitute or imply its endorsement, recommendation, or favoring by the United States government or any agency thereof. The views and opinions of authors expressed herein do not necessarily state or reflect those of the United States government or any agency thereof.

Available electronically at http://www.osti.gov/bridge

Available for a processing fee to U.S. Department of Energy and its contractors, in paper, from:

U.S. Department of Energy

Office of Scientific and Technical Information

P.O. Box 62

Oak Ridge, TN 37831-0062

phone: 865.576 .8401

fax: 865.576 .5728

email: mailto:reports@adonis.osti.gov

Available for sale to the public, in paper, from:

U.S. Department of Commerce

National Technical Information Service

5285 Port Royal Road

Springfield, VA 22161

phone: 800.553.6847

fax: 703.605.6900

email: orders@ntis.fedworld.gov

online ordering: http://www.ntis.gov/ordering.htm 


\section{Abstract}

Hydrogen gas leaking from a hydrogen-powered vehicle in a residential garage may form a

flammable mixture with air. Passive, buoyancy-driven ventilation is one approach to limiting the concentration to a safe level. We explored the relationship between leak rate, ventilation design, and hydrogen concentration through laboratory testing, an algebraic analysis, and CFD

modeling. We used helium to test slow, steady, low-velocity leaks in a full-scale test room under nearly isothermal, steady conditions, and we report the results in sufficient detail that other modelers can use them. The results show the importance and variability of stratification. Our algebraic and CFD models agree very well with the experimental results. We describe our CFD approach in sufficient detail for use by others. We tested under nearly isothermal conditions, but also discuss indoor-outdoor temperature difference as an important risk factor. Information about realistic leakage scenarios is needed to apply these results as safety recommendations. 


\section{Acknowledgments}

This work was funded by the Hydrogen Safety, Codes and Standards program of the U.S.

Department of Energy's (DOE) Office of Hydrogen, Fuels Cells and Infrastructure Technologies at NREL's Hydrogen Technologies and Systems Center, in collaboration with NREL's Buildings and Thermal Systems (BTS) Center. DOE program director Antonio Ruiz and NREL project managers Jim Ohi, Chad Blake, and Carl Rivkin provided valuable guidance and support. The support of BTS managers Ron Judkoff and Ren Anderson was also essential. NREL technician Matthew Post and test engineer Ed Hancock, with Mountain Energy Partnership, were helpful in crafting and installing the laboratory apparatus. 


\section{Nomenclature}

c $=$ Concentration of hydrogen, by volume (dimensionless, $0-1$ in formulas, $0 \%-100 \%$ in tables and graphs)

$\mathrm{g}=$ Acceleration of gravity $=9.81 \mathrm{~m} / \mathrm{s}^{2}$

$\mathrm{h}=$ Height between vents, $\mathrm{m}$

$\mathrm{y} \quad=$ Vertical distance above floor, $\mathrm{m}$

$\mathrm{A}=$ Vent area (top $=$ bottom), $\mathrm{m}^{2}$

$\mathrm{A}^{\prime} \quad=$ Vent area (top $=$ bottom) adjusted for test room leakage, $\mathrm{m}^{2}$

$\mathrm{ADR}=$ Air density ratio $=($ local atmospheric pressure $) /($ sea level atmospheric pressure $)$ (dimensionless)

$\mathrm{CFM}=$ Cubic feet per minute, $\mathrm{ft}^{3} / \mathrm{min}$

$\mathrm{D}=$ Vent discharge coefficient (dimensionless, 0-1)

$\mathrm{D}_{1}=\mathrm{D}$ based on Equations 6 and 7 (dimensionless, 0-1)

$\mathrm{D}_{2}=\mathrm{D}$ based on Equations 6 and 8 (temperature compensated) (dimensionless, 0-1)

$\mathrm{F}=$ Vent sizing factor (dimensionless)

L\# (1-2) $=$ Laboratory test number using the linear diffuser

$\mathrm{L}_{\mathrm{E}}=$ Entrainment length, $\mathrm{m}$

$\mathrm{LPM}=$ Liters per minute at local conditions, $\mathrm{L} / \mathrm{m}$

$\mathrm{NLPM}=$ Liters per minute at $\mathrm{NTP}\left(20^{\circ} \mathrm{C}\right.$ and $\left.1 \mathrm{~atm}\right), \mathrm{L} / \mathrm{m}$

$\mathrm{NTP}=$ Normal temperature and pressure $\left(20^{\circ} \mathrm{C}\right.$ and $\left.1 \mathrm{~atm}\right)$

$\mathrm{P} \quad=$ Total pressure $(\mathrm{Pa})$

P\# (1-6) = Laboratory test number using the point diffuser

$\mathrm{Q}=$ Volumetric flow rate through a vent, $\mathrm{m}^{3} / \mathrm{s}$

$\mathrm{S}=$ Source rate of hydrogen (leak rate), $\mathrm{m}^{3} / \mathrm{s}$ in formulas, LPM in discussions

$\mathrm{T}=$ Temperature, $\mathrm{K}$

$\delta=$ Ratio of densities of hydrogen or helium to air at NTP (dimensionless) $=0.0695$ for hydrogen, 0.1368 for helium

$\theta=$ Thermal buoyancy ratio (dimensionless)

$\rho \quad=$ Density, $\mathrm{kg} / \mathrm{m}^{3}$

$\varphi=$ Stratification factor $=\mathrm{c}_{\mathrm{T}} / \mathrm{c}_{\mathrm{avg}}$ (dimensionless)

$\Delta \quad=$ Difference

\section{Subscripts:}

1 to 9 Sequence of gas sampling points from floor to ceiling

avg Spatial average over the height between vents inside the test room

i Inside test room

o Outside of test room, within building

$\mathrm{x} \quad$ Transition height

B Bottom vent

Leak Leakage through cracks in test room

$\mathrm{S} \quad$ Source of vehicle leakage or gas injection in the test room

$\mathrm{T}$ Top vent 


\section{Contents}

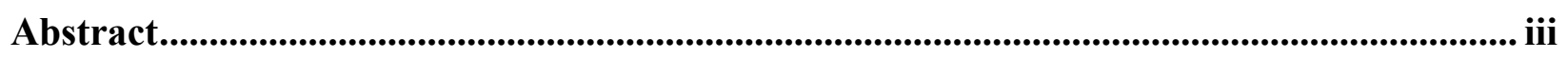

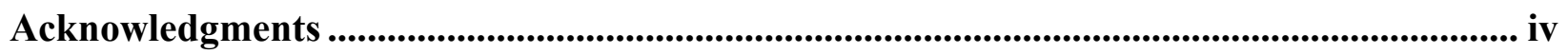

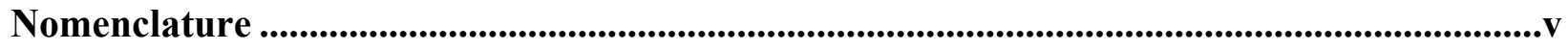

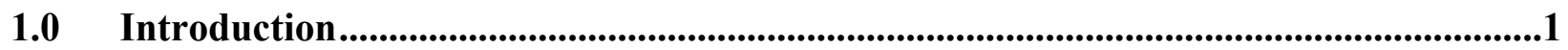

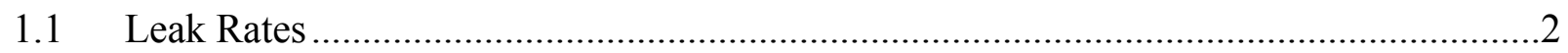

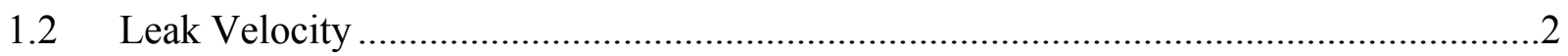

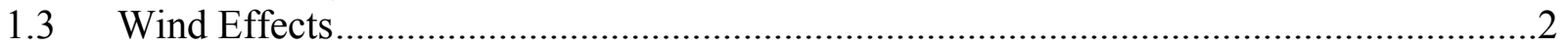

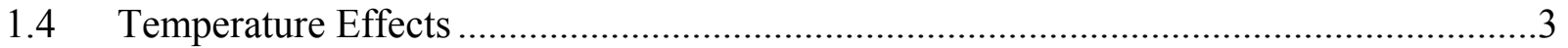

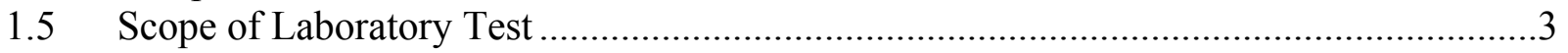

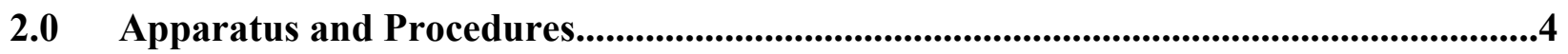

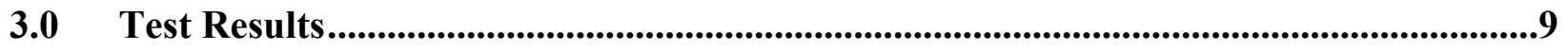

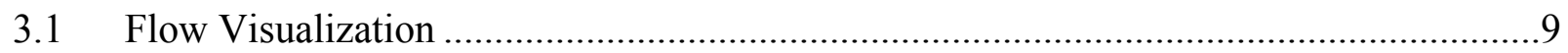

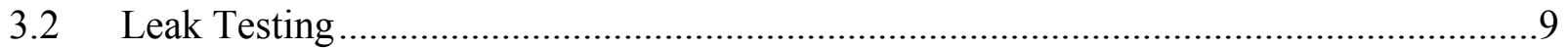

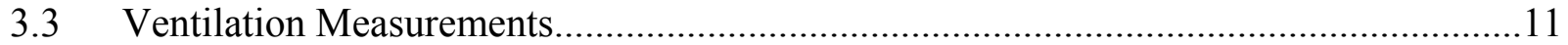

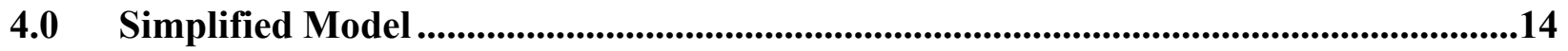

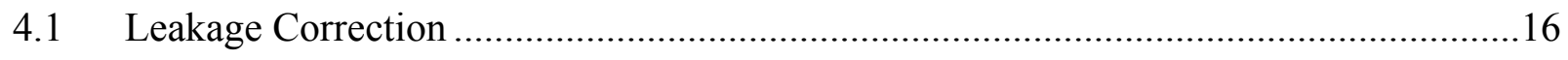

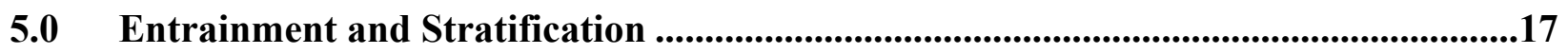

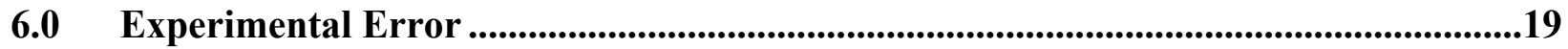

7.0 Computational Fluid Dynamics Model Validation ..........................................................20

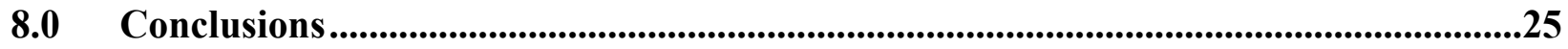

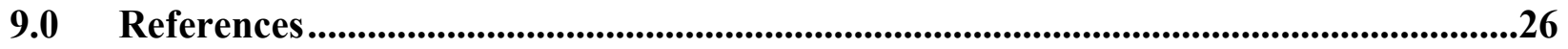




\subsection{Introduction}

This study addresses the safety issue of hydrogen gas leakage within a building, as from a hydrogen-powered vehicle parked in a residential garage. Any leakage of unignited hydrogen will mix with indoor air and may form a flammable mixture. The most widely accepted flammability range is $4.1 \%$ to $75 \%$ hydrogen by volume [1]. To provide a safety margin, many standards [e.g., 2,3] specify a safe limit of $25 \%$ of the lower flammability limit (LFL), which for hydrogen amounts to $1 \%$ by volume. Passive (buoyancy-driven) and active (mechanical) ventilation strategies may be used to prevent the accumulation of hydrogen at flammable concentrations; both approaches have limitations. Researchers need to understand the relationship between leakage scenario, ventilation design, and hydrogen concentration to develop safety standards and codes to address this risk.

Previous studies of indoor hydrogen leaks have employed simplified analyses, computational fluid dynamics (CFD) modeling, and laboratory testing. Swain and Swain [4] modeled transient accumulation of hydrogen within a cloud above a leak in a passively ventilated room, with leak rates of 10 to 1000 LPM. Breitung et al. [5] modeled transient hydrogen cloud formation resulting from pulsed releases of small amounts of hydrogen (insufficient to form a combustible concentration if fully mixed in the enclosure). Venetsanos et al. [6] conducted a CFD intercomparison exercise in which 12 participants modeled an experimental transient release of hydrogen into a garage-sized enclosure, with pressure-relief vents only. Those comparisons emphasize the sensitivity of the results to the modeling approach; the key variables are turbulence model, time and space resolution, and discretization scheme. Swain et al. used helium to study leakage scenarios experimentally [7] and tested hydrogen ignition and combustion scenarios $[8,9,10]$. Helium is useful in experimental work because (1) it avoids the hazard of possible ignition during the experiment, (2) its physical properties are similar to those of hydrogen, ${ }^{1}$ and (3) it is straightforward to account for the differences between hydrogen and helium in the models. Gupta et al. [12] tested transient releases of helium in a garage-sized enclosure with a pressure-relief vent only. Papanikolaou and Venetsanos [13] modeled three of the helium experiments performed by Swain et al. Wilkening and Baraldi [14] used CFD to simulate and compare outdoor releases of hydrogen and methane gas from a pierced pipeline. Venetsanos and Bartzis [15] modeled outdoor releases of liquid hydrogen and compared CFD predictions with experimental results. Schmidt et al. [16] modeled outdoor release of gaseous hydrogen and compared results obtained with the FLUENT ${ }^{\circledR}$ software- which we also usewith those of other CFD software and with experimental results.

Our study specifically addresses a slow, sustained, indoor hydrogen gas leak that, over time, may develop a flammable mixture throughout a large portion of the garage volume. We have previously reported [17] analysis results, which include a simplified, one-dimensional, steadystate analysis of buoyancy-driven ventilation (Section 4), and CFD modeling (Section 7). The simplified model yields an algebraic formula relating hydrogen concentration to vent size, height, and discharge coefficient; leakage rate; and stratification factor. However, the stratification factor depends on dynamics that are beyond the scope of the simple model. The CFD model provides additional detail, including the stratification factor. In addition to our discovery of parametric relationships among the variables, we believe our study is the first to

\footnotetext{
${ }^{1}$ Although helium is almost twice as dense as hydrogen, the buoyancy relative to the density of air is $93 \%$ for hydrogen and $86 \%$ for helium. The diffusivities in air are $0.756 \mathrm{~cm}^{2} / \mathrm{s}$ for hydrogen and $0.697 \mathrm{~cm}^{2} / \mathrm{s}$ for helium at NTP [11].
} 
describe the significant thermal effect that occurs when the outdoor air temperature is higher than the indoor air temperature, so that thermally driven air circulation opposes the effect of hydrogen buoyancy. The isothermal condition is an important reference case that we address in this article, which describes our laboratory testing and comparison of experimental results with model predictions.

\subsection{Leak Rates}

Because the hydrogen-powered vehicle is an emerging technology, we do not yet have a statistically significant set of historical data describing accidental leak rates. Schefer et al. [18] present equations for calculating leak rates in various flow regimes, based on leak diameter. If these equations were coupled with physical descriptions of vehicle component failure modes (which are not yet available), corresponding leak rates could be calculated. Draft Standard SAE J2578 [19] tentatively prescribes a maximum allowed leak rate of 0.15 LPM for a standard passenger vehicle leaving a factory. However, the possibility of higher leak rates resulting from faulty maintenance, collision damage, or other degradation of components after the car leaves the factory should also be considered. Parsons Brinkerhoff [20] cites a hypothetical "on-board computer that is capable of shutting down hydrogen flow upon receiving a signal detecting a larger than 20 CFM [566 LPM] flow, 'leak,' when the vehicle is dormant." Thus, we may consider the range of "slow" leaks as roughly 0.15 to 566 LPM. A much higher leakage rate of about 30,000 LPM may occur when a pressure relief device is triggered; however, it does not seem practical to design a building ventilation system that can prevent a combustible mixture under this condition. We used leak rates ranging from 2.4 to 50 LPM in laboratory testing.

\subsection{Leak Velocity}

Leakage of hydrogen from a fuel system with expected pressures of about 35 to $70 \mathrm{MPa}$ may occur at a high velocity in an arbitrary direction. Such a high-velocity leak may agitate and mix room air with hydrogen, minimizing stratification. However, if the leak occurs within the body of a vehicle, hydrogen may emerge from the vehicle at a much lower velocity. ${ }^{2}$ Another lowvelocity leak scenario is boil-off of liquid hydrogen. A low-velocity leak minimally agitates room air and thus enables more hydrogen stratification. For a given vent size and leak rate, more stratification leads to higher concentrations of hydrogen in the room (Section 4). Thus, for passive ventilation as a safety approach, a low-velocity leak is worse than a high-velocity leak. We used low leak velocities in our analyses and testing to explore worst-case conditions. A possible exception to this generalization might be a leak jet directed toward an inlet vent, so that the leak momentum opposes buoyancy-driven influx of outside air.

\subsection{Wind Effects}

Wind pressure on a building may affect buoyancy-driven ventilation of hydrogen. The wind may help or hinder ventilation, depending on the wind direction relative to the inlet and outlet vent locations. One approach to minimizing the likelihood of adverse wind effects is to locate the inlet (bottom) vent on the prevailing upwind side of the building and the outlet (top) vent on the prevailing downwind side. In this configuration, the prevailing winds are more likely to augment than to oppose the buoyancy-driven flow. Another approach, where architecturally feasible, is to distribute the high vent area among several outside walls of different orientations,

\footnotetext{
${ }^{2}$ The accumulation of hydrogen inside the body of the car poses an additional risk.
} 
so that wind in any direction would drive cross-ventilation, thus assisting the buoyancy-driven ventilation. Assuming that negative wind effects can be avoided architecturally, the absence of wind is a worse case than windy conditions, so we conducted our modeling and laboratory testing in the absence of wind.

\subsection{Temperature Effects}

Buoyancy-driven ventilation is very sensitive to temperature differences. For example, a $1 \%$ change in the density of air, which determines the driving force for vent flow, may be caused by a $1.07 \%$ concentration of hydrogen, $1.16 \%$ helium, or a $3 \mathrm{~K}$ difference in temperature (based on the ideal gas law at $300 \mathrm{~K}$ ). Thus, in a residential garage application, outdoor air that is a few degrees warmer than the indoor air would have a significant effect on the hydrogen concentration resulting from a leak; such thermal conditions occur frequently in most climates. Thermocirculation (the stack effect) opposes the buoyancy-driven ventilation of hydrogen, and warmer outside air may enter the top vent while hydrogen accumulates near the ceiling. This effect, which we modeled in our previous paper [17], is a significant concern for the reliability of buoyancy-driven ventilation as a safety approach. However, the isothermal condition is an important reference case for model validation and other purposes, and we address this case in our testing.

\subsection{Scope of Laboratory Test}

We tested buoyancy-driven ventilation of helium in a full-scale test room, about the size of a typical one-car garage. This room is shielded from the wind inside a conditioned laboratory building. We tried to test under isothermal conditions, although there was some temperature variation during the tests (Section 2). We tested low-velocity leakage at rates of 2.4 to $50 \mathrm{LPM}$, although cases lower than 9 LPM are not reported because of the interference of thermal effects (Section 3.3). In addition to reporting the experimental data, we also show the correspondence of the data to both our simplified model and our CFD model, which we improved through this exercise. We describe in detail the CFD model features with which we achieved good agreement. 


\subsection{Apparatus and Procedures}

The test room (Figures 1 and 2) is located inside the Thermal Test Facility building at the National Renewable Energy Laboratory (NREL) in Golden, Colorado. At 1,800 m above sea level, the nominal air density ratio (ADR) is 0.804 [21]. During our tests, we measured the atmospheric pressure with a mercury-column barometer attached to the outside of the test room. According to our simple model (Section 4), atmospheric pressure does not influence the relationship between design variables in volumetric terms. (The effect of density on the buoyancy force is offset by its effect on the pressure drops through the vents.) We represented the actual pressure in the CFD model and studied sensitivity to this variable (Section 7). We also used the pressure measurements to convert gas flow rates (S) from NLPM in the flow control valve to LPM in Table 1 (Section 3.3).

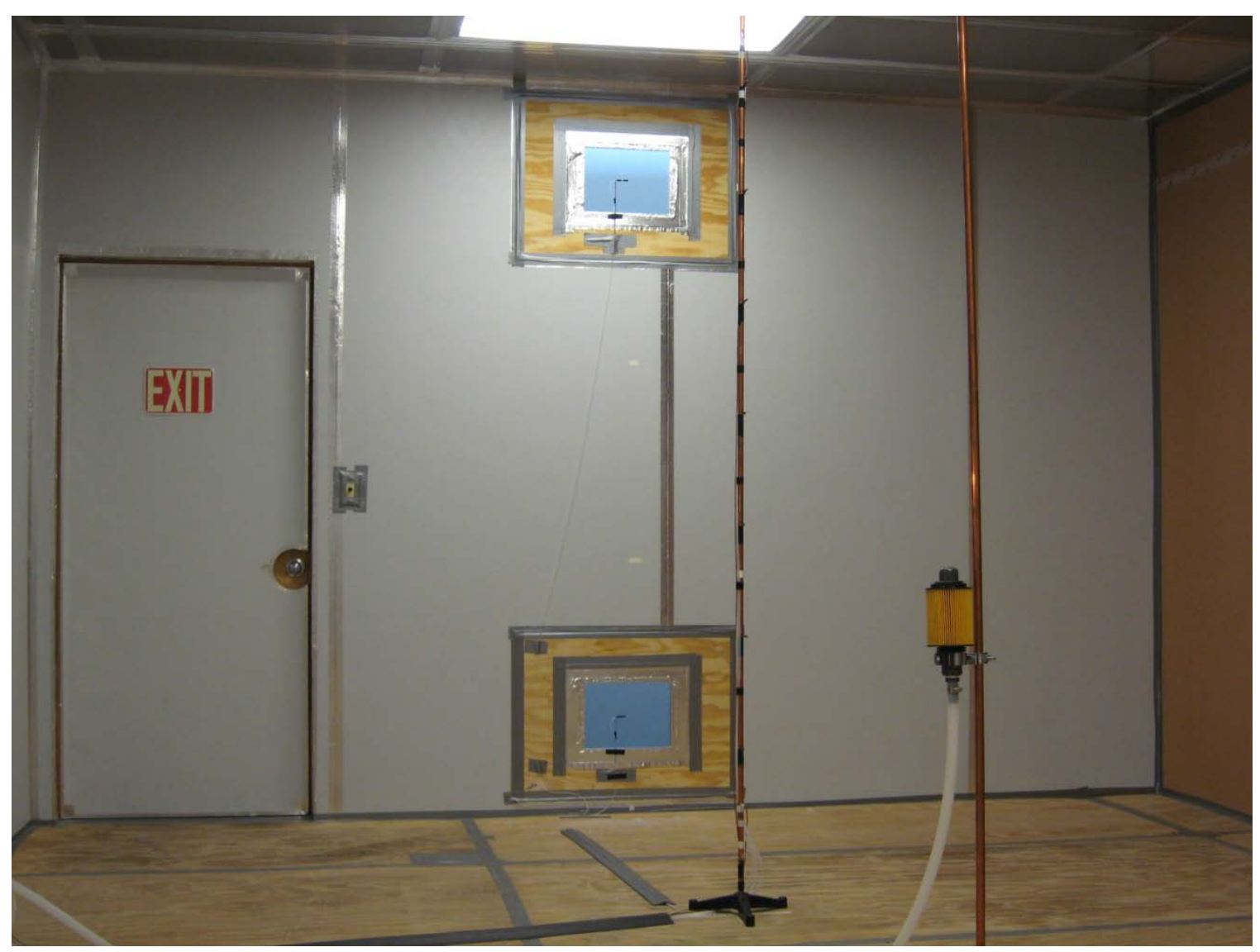

Figure 1. Inside of test room, showing point diffuser, sampling column, vents, and door 


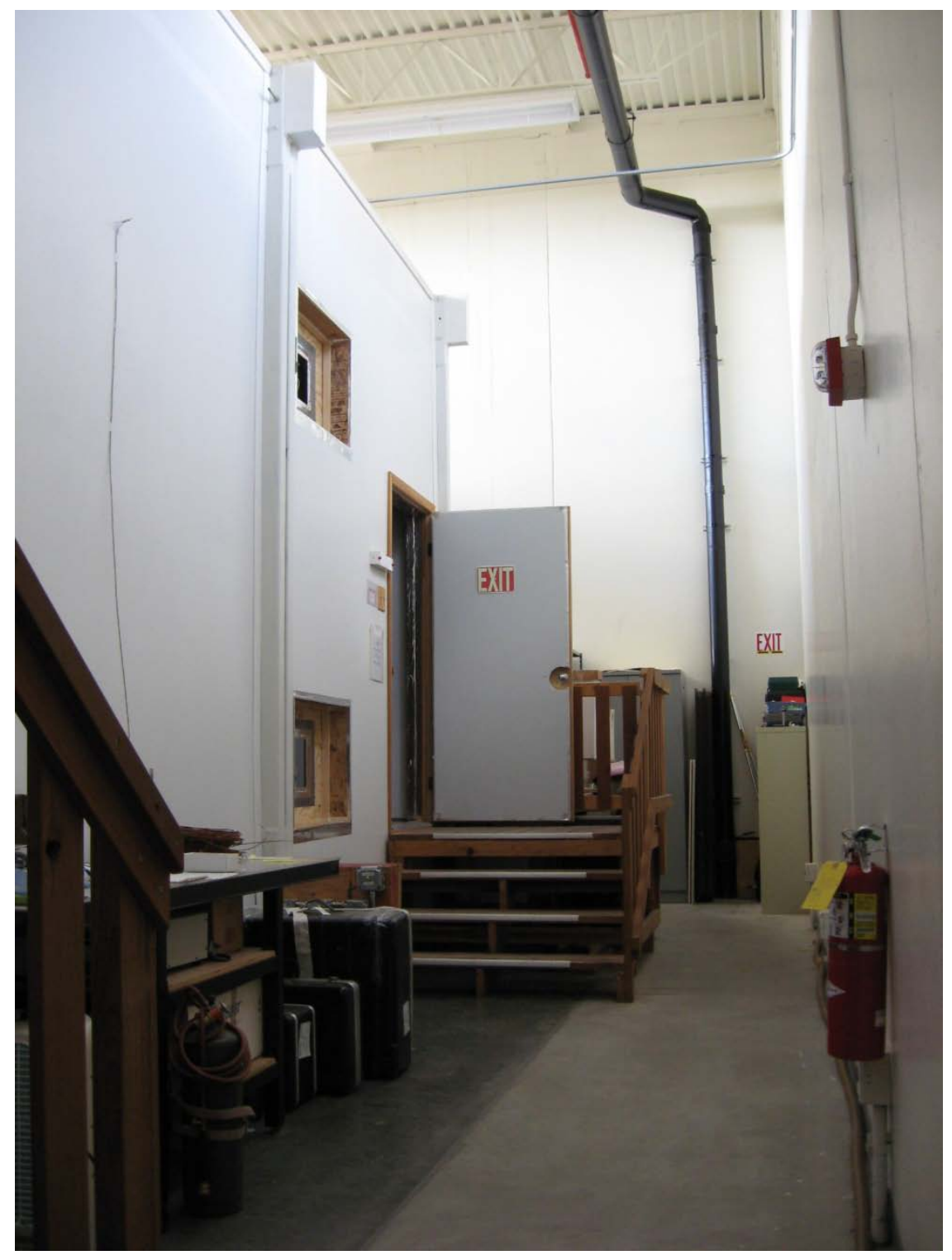

Figure 2. Outside of test room, showing vents and door. The distance between the test room and the building wall is $2.44 \mathrm{~m}$. 
The test room is a rectangular prism measuring $4.29 \mathrm{~m}$ wide, $7.02 \mathrm{~m}$ long, and $2.74 \mathrm{~m}$ high. The two vents were open rectangles cut in 11.1-mm (7/16-in.) plywood panels located in one of the end walls (4.29 $\mathrm{m}$ wide). The vents were horizontally centered in the wall, with their centers $36.8 \mathrm{~cm}$ above the floor and below the ceiling; thus, the height between the vent centers (h) was $2.01 \mathrm{~m}$. The vent openings were $32.4 \mathrm{~cm}$ wide by $24.3 \mathrm{~cm}$ high. The plywood vent panels were installed in channels cut through the test room wall, $81 \mathrm{~cm}$ wide, $61 \mathrm{~cm}$ high, and $17.1 \mathrm{~cm}$ deep (Figure 2). These channels were sized so that $97.5 \%$ of the flow pressure drop occurred across the vent cutouts. Thus, the vent geometry approximated a rectangular hole in a large, thin wall. To minimize air leakage from the test room, we replaced acoustical ceiling tiles with acrylic light lenses and sealed the edges with metallic tape. We also taped all obvious cracks in the walls and floor, and applied weatherstripping to the door. The floor material is plywood. Three of the interior wall surfaces consist of aluminum-clad foam insulation of the type used for walk-in coolers, and the fourth wall surface is foam core. A glass window $(2.31 \mathrm{~m}$ wide and $2.11 \mathrm{~m}$ high) in one of the side walls separates the test room from the instrument room. We tested the helium leakage rate from the room with the vents closed and corrected for this leakage in our calculations (Section 4.1). The effective leakage area was about $1 \%$ of the vent area.

We released compressed helium gas from a tank outside the test room through a mass flow control valve (Porter model 202, factory calibrated for 0 to 100 NLPM of helium) into the test room through one of two low-velocity diffusers. The "point" diffuser consisted of an automobile oil filter element ${ }^{3}$ with a cylindrical height of $9.6 \mathrm{~cm}$ and diameter $8 \mathrm{~cm}$ (Figure 1; Figures 5 and 6 in Section 3). The active area was the curved side only: $242 \mathrm{~cm}^{2}$. Thus, with the highest helium injection rate of $50 \mathrm{LPM}$, the injection velocity was only $3.45 \mathrm{~cm} / \mathrm{s}$. The point diffuser was located at variable height above the center of the test room floor ( $y_{s}$ in Table 1, Section 3). The "line" diffuser consisted of a 1.83-m length of $17.5 \mathrm{~mm}$ (11/16-in.) outside diameter, porous rubber, garden-type soaker hose (Figure 3), positioned $61 \mathrm{~cm}\left(\mathrm{y}_{\mathrm{s}}\right)$ above the floor for Cases L1 and L2. The surface area of the soaker hose was $1,003 \mathrm{~cm}^{2}$, of which $260 \mathrm{~cm}^{2}$ was loosely wedged into the angle-aluminum support bar and $743 \mathrm{~cm}^{2}$ was unobstructed. Thus, with our highest helium injection rate used with the line diffuser, 40.4 LPM, the injection velocity was only $0.91 \mathrm{~cm} / \mathrm{s}$, based on the unobstructed area. The linear release pattern might be more similar to hydrogen escaping from under the body of a vehicle than the point release pattern.

We used a thermal conductivity gas analyzer (Teledyne 2000A-EU) to measure helium concentration, drawing samples through a system of $1.59-\mathrm{mm}(1 / 16-\mathrm{in}$.) inside diameter polyethylene tubing and manual valves from 11 locations in the test room. These locations included a column of nine sample points centered in each foot of height between the floor and ceiling, ${ }^{4}$ and one sample point in the center of each vent (Figure 1). The sampling column was located halfway between the injection diffuser and the vents. ${ }^{5}$ We used a tank of compressed air for the reference gas and zero calibration, and calibrated the measurement scale (span) to a compressed sample certified as $3.99 \pm 0.04 \%$ helium in air. We adjusted the linearity correction function in the instrument to match a second sample certified as $2.01 \pm 0.02 \%$ helium in air, with quadratic interpolation between the three reference points $(0.00 \%, 2.01 \%$, and $3.99 \%)$. Before any helium was released into the room, the instrument indicated a significant nonzero

\footnotetext{
${ }^{3}$ We chose this object based on its size, shape, and porosity to provide a low leak velocity. This is not intended to represent an actual leakage path in a vehicle.

${ }^{4}$ These are numbered 1 to 9, from floor to ceiling, in Table 1.

${ }^{5}$ According to our CFD model results (Section 7, Figure 10), the vertical concentration profile is rather uniform across the length and width of the test room.
} 
measurement of indoor air - the room zero offset (RZO) - which is correlated to humidity ratio in Figure 4. Values of RZO ranged from $0.04 \%$ to $0.19 \%$ in the test cases. Because the test room is enclosed in a building, background helium concentrations of $0.01 \%$ to $0.10 \%$ accumulated in the air inside the building and outside the test room. We corrected for the combined effects of humidity and background helium by sampling the air entering the bottom vent and subtracting this measurement from all 11 samples for each steady-state measurement shown in Table 1. Thus, each measurement at the bottom vent (column B in Table 1) is zero by procedure. We deemed conditions to be steady when changes in the concentration measurements, on the order of hundredths of a percent over several minutes, tended to oscillate rather than drift in one direction. The elapsed times to steady state ranged from 72 to 190 minutes in the test cases; the longest times corresponded to thermal transients in the building.

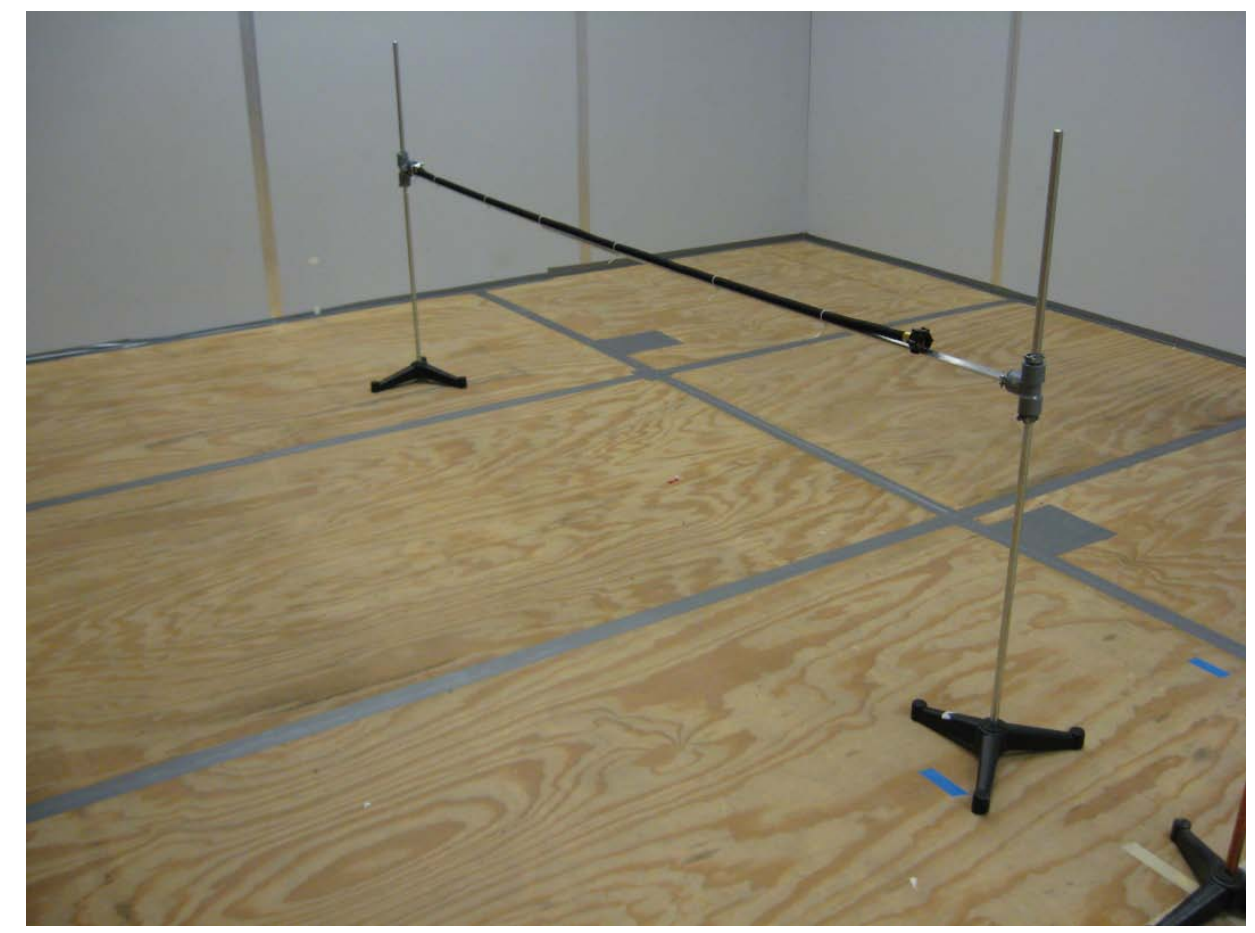

Figure 3. Line diffuser used to inject helium in Cases L1 and L2

We also tested the sensitivity of the measurement of the calibration gas to length of tubing, between the shortest $(3.66 \mathrm{~m})$ and longest $(9.14 \mathrm{~m})$ sample tube lengths, and observed no measurable sensitivity to length. This result rules out significant effects of flow resistance through the tubing, diffusion of helium through the tubing, or contamination of the sample gas by the tubing material. 


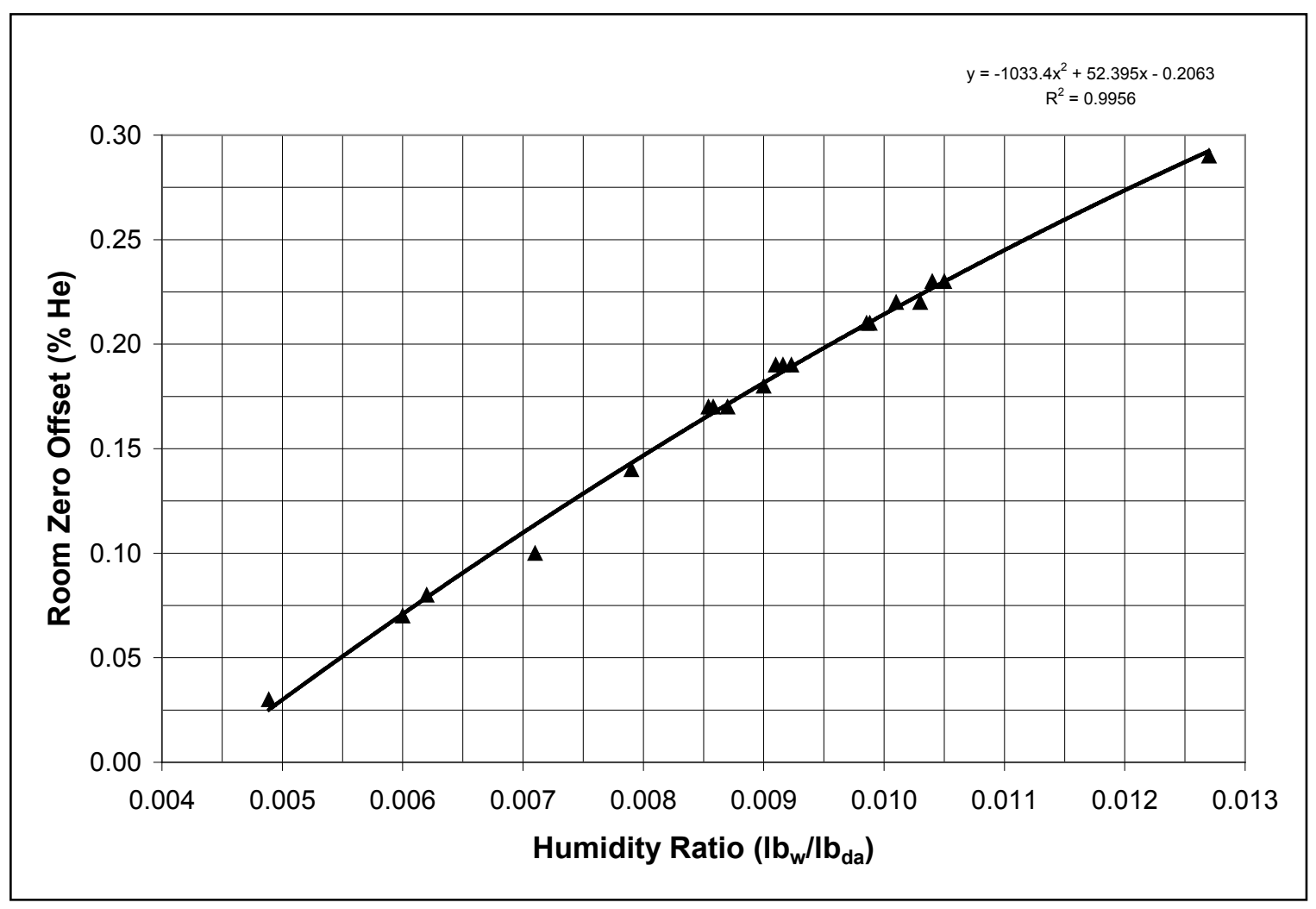

Figure 4. Measured effect of humidity on gas analyzer indication

We tried to maintain isothermal conditions between the test room and the surrounding building. This is both challenging and critical, because a temperature difference as slight as $0.3 \mathrm{~K}$ corresponds to about $0.1 \%$ helium in density effect, ${ }^{6}$ which is a significant measurement concern. We used shielded thermocouples to monitor temperatures at the heights of each vent, both inside and outside the test room. The $\Delta \mathrm{T}$ reported in Table 1 is the inside temperature minus the outside temperature, averaged over the two measurement heights. $T_{i}$ is the average of the two inside temperatures. For an analysis of thermal effects, the temperature profile between the vent heights should be measured inside and outside the test room. The $\Delta \mathrm{T}$ we measured provides only a rough indication of the relevant thermal condition. Two temperature control problems arose:

Temporal variations. Because of its heat capacity, the test room lagged the building as the temperature varied between the heating and cooling control setpoints because of equipment cycling and changes in the weather, solar gains, and occupant behavior. To minimize these variations, we conducted testing overnight during steady, cool weather when practical.

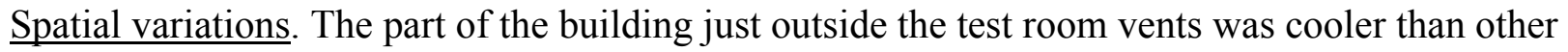
parts of the building because of a nearby below-grade outside wall. By virtue of heat exchanges through the other test room walls, the test room was generally warmer than the air just outside the vents.

Temperature variations are discussed further in Section 3.3.

\footnotetext{
${ }^{6}$ See discussion in Section 1: Temperature effects, and Equation 1 (Section 3.3) with $\theta=1$.
} 


\subsection{Test Results}

We conducted three phases of testing:

- Flow visualization

- Test room leakage measurement with vents closed

- Ventilation measurements with vents open.

\subsection{Flow Visualization}

Figures 5 and 6 illustrate a flow visualization test we conducted using smoke generated by two burning paraffin wicks (Regin 220 Smoke Pen) near the helium point diffuser. Figure 5 shows the undisturbed smoke streams before any helium was released. Figure 6 shows the deflection of the smoke with a release rate of 20 LPM, demonstrating (1) negligible radial displacement of helium away from the diffuser; (2) horizontal entrainment of air into the helium plume above the diffuser; and (3) laminar flow of the entrained smoke. Based on our observations at the time of the test, the lack of a visible smoke stream from the wick above the center of the diffuser was due to the high vertical velocity of the plume at that location. An additional test with a release rate of 100 LPM showed no visible difference from the 20 LPM case. The laminar appearance of the smoke stream supports the use of the laminar CFD model (Section 7). The relationship between air entrainment and helium stratification is discussed in Section 5.

\subsection{Leak Testing}

To test the rate of helium leakage from our test room with the vents closed, we initially planned to use the following procedure to perform a constant-concentration test:

- Inject helium and mix the room air with a fan until a uniform target concentration is achieved.

- Turn off the fan and adjust the helium injection rate to maintain a constant concentration.

- Record the steady-state concentration and injection rate.

However, the leakage rate was below the functional range of the flow control valve. Thus, we used this alternative decay test procedure:

- Inject helium and mix the room air with a fan until a uniform target concentration is achieved.

- Turn off the fan and the helium injection.

- Wait for a period of time.

- Record the elapsed time and the helium concentration profile.

The test results are as follows:

- Initial concentration (uniform)

- Elapsed time

- Final concentration (average over height)

- Volume of test room

- Rate of helium loss
$2.96 \%$

70 minutes

$2.91 \%(\varphi \approx 1)$

$82.7 \mathrm{~m}^{3}$

$0.60 \mathrm{LPM}$

We corrected the ventilation measurements for test room leakage as described in Section 4.1. 


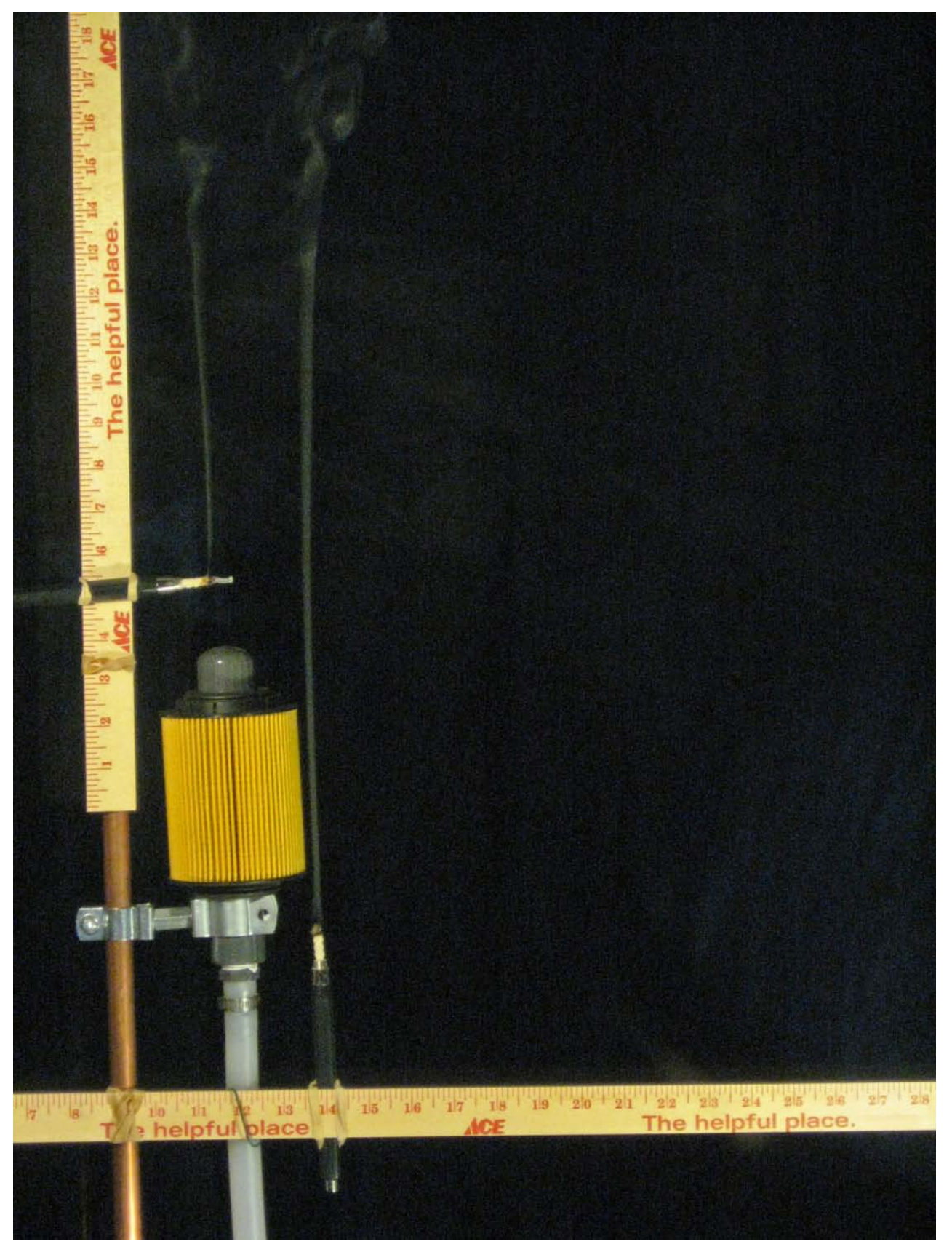

Figure 5. Smoke visualization with no helium release. Linear distance scales are in inches. 


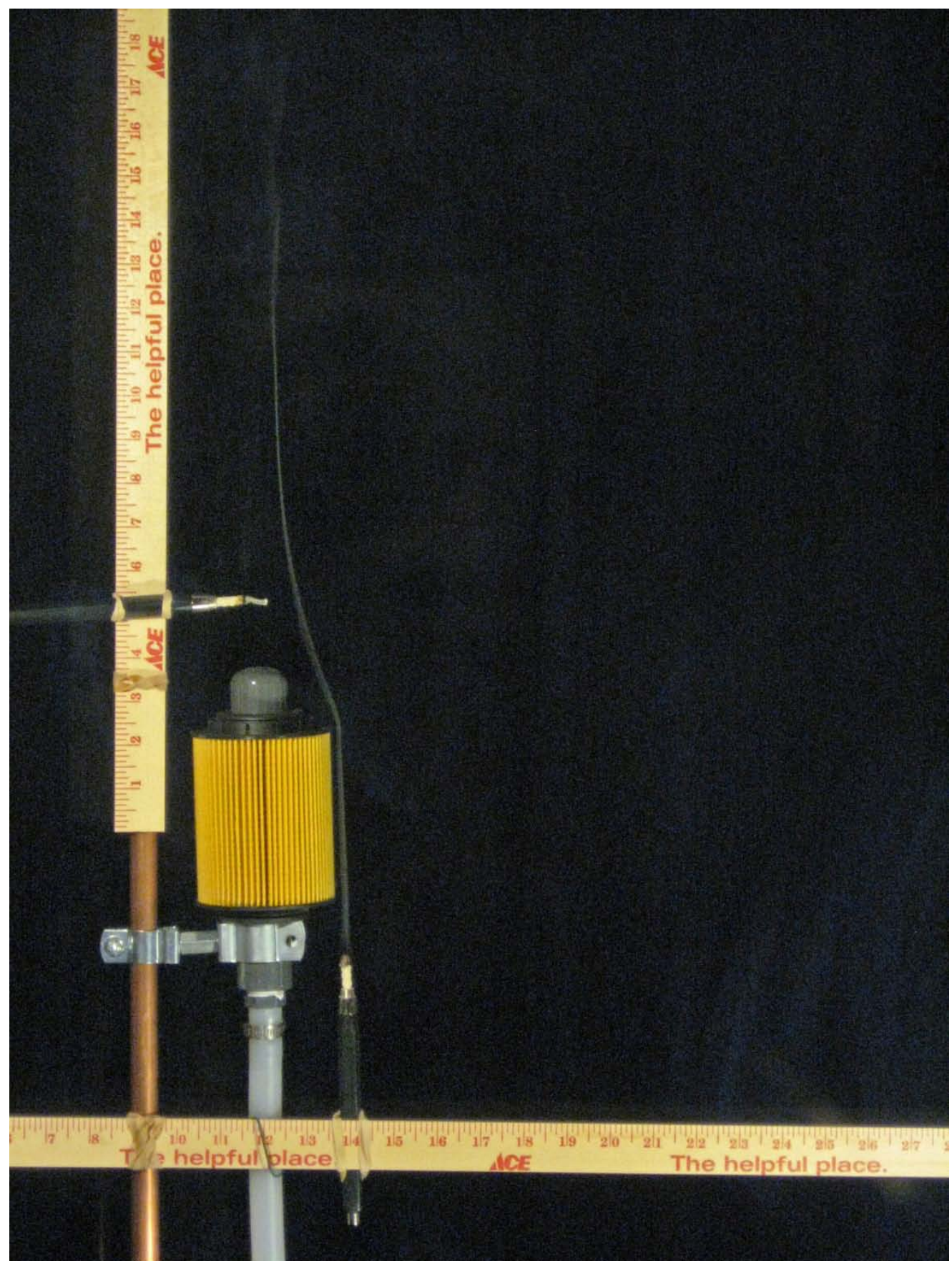

Figure 6. Smoke visualization with 20 LPM helium release. Linear distance scales are in inches.

\subsection{Ventilation Measurements}

Results of the ventilation tests are shown in Tables 1 and 2. The letter "P" in the case number indicates use of the point diffuser, and the letter " $\mathrm{L}$ " indicates the line diffuser (Section 2). Table 1 shows direct measurements. These concentration data are corrected for humidity and 
background helium as described in Section 2. Table 2 shows derived results that are discussed in the following sections.

In order to gauge the significance of the thermal effects related to $\Delta \mathrm{T}$ (Section 2; Table 1), we define the metric $\theta$ as the ratio of the effect on air density caused by the temperature difference to that caused by the helium concentration (with $\mathrm{T}$ in $\mathrm{K}$ ):

$$
\theta=\frac{1-\frac{T_{o B}+T_{o T}}{T_{i B}+T_{i T}}}{c_{a v g}(1-\delta)}
$$

A value of $\theta=0$ indicates no thermal effect (isothermal conditions), and a value of $\theta=1$ indicates a thermal effect that is equal to the helium effect. This comparison is only approximate, because the measurement of temperature at two heights does not capture the temperature stratification profile, which also affects the dynamics. The values of $\theta$ shown in Table 2 range from 0.05 to 0.40 . The three test cases most closely approximating isothermal conditions (with the lowest values of $\theta$ ) are P4, L1, and L2. We used Case P4 in the CFD model validation exercise (Section 7). Four additional test cases, not shown in Tables 1 and 2, yielded values of $\theta>0.5$. These cases include three with $\mathrm{S}<9 \mathrm{LPM}$ and one with $\Delta \mathrm{T}=0.8 \mathrm{~K}$. The derived results for each of these cases stand out as anomalies that are not consistent with the other cases. We believe the cause of the anomalies is the relatively large deviation from isothermal conditions. A more detailed study of thermal effects is beyond the scope of this experiment, because of the limited temperature measurements we recorded.

Table 1. Measured Test Results

\begin{tabular}{|c|c|c|c|c|c|c|c|c|c|c|c|c|c|c|c|c|}
\hline \multirow[t]{2}{*}{ Case } & \multirow{2}{*}{$\begin{array}{l}y_{S} \\
(m)\end{array}$} & \multirow{2}{*}{$\begin{array}{c}S \\
\text { (LPM) }\end{array}$} & \multirow{2}{*}{\begin{tabular}{|c|}
$P_{\mathrm{o}}$ \\
$(\mathrm{mm}-\mathrm{Hg})$ \\
\end{tabular}} & \multirow{2}{*}{$\begin{array}{l}\Delta \mathrm{T} \\
(\mathrm{K})\end{array}$} & \multirow{2}{*}{$\begin{array}{c}T_{i} \\
(K)\end{array}$} & \multicolumn{11}{|c|}{ He Concentration (\%) } \\
\hline & & & & & & B & $\mathbf{T}$ & 1 & 2 & 3 & 4 & 5 & 6 & 7 & 8 & 9 \\
\hline & & & & & & & & & & & & & & & & \\
\hline $\mathrm{P} 1$ & 0.61 & 9.8 & 622 & 0.42 & 297.2 & 0.00 & 1.19 & 0.00 & 0.00 & 0.00 & 0.06 & 0.19 & 0.56 & 0.92 & 1.14 & 1.17 \\
\hline $\mathrm{P} 2 \mathrm{a}$ & 0.61 & 22.0 & 622 & 0.53 & 297.2 & 0.00 & 2.00 & 0.00 & 0.01 & 0.02 & 0.11 & 0.35 & 0.93 & 1.61 & 2.00 & 2.02 \\
\hline $\mathrm{P} 2 \mathrm{~b}$ & 0.61 & 22.0 & 622 & 0.58 & 297.2 & 0.00 & 1.97 & 0.00 & 0.01 & 0.02 & 0.09 & 0.33 & 0.91 & 1.60 & 1.96 & 1.99 \\
\hline P3 & 0.61 & 40.3 & 622 & Unk & 296.4 & 0.00 & 2.86 & 0.01 & 0.02 & 0.03 & 0.09 & 0.47 & \begin{tabular}{|l|}
1.42 \\
\end{tabular} & 2.43 & 2.85 & 2.87 \\
\hline P4 & 0.91 & 12.3 & 622 & 0.22 & 296.3 & 0.00 & 1.49 & 0.00 & 0.00 & 0.01 & 0.02 & 0.12 & 0.48 & 0.98 & 1.43 & 1.51 \\
\hline P5 & 0.91 & 24.5 & 619 & 0.61 & 296.0 & 0.00 & 2.47 & 0.01 & 0.01 & 0.02 & 0.04 & 0.14 & 0.57 & 1.45 & 2.34 & 2.56 \\
\hline $\mathrm{P} 6$ & 1.22 & 18.4 & 619 & 0.36 & 296.1 & 0.00 & 2.16 & 0.00 & 0.00 & 0.00 & 0.02 & 0.06 & 0.28 & 0.75 & 1.84 & 2.67 \\
\hline L1 & 0.61 & 22.0 & 625 & 0.14 & 295.6 & 0.00 & 1.66 & 0.08 & 0.17 & 0.40 & 1.26 & 1.58 & 1.64 & 1.65 & 1.66 & 1.66 \\
\hline L2 & 0.61 & 40.4 & 625 & 0.25 & 295.5 & 0.00 & 2.40 & 0.13 & 0.27 & 0.71 & 1.97 & 2.33 & 2.38 & 2.39 & 2.41 & 2.42 \\
\hline
\end{tabular}


Table 2. Derived Test Results

\begin{tabular}{|c|c|c|c|c|c|c|c|c|}
\hline Case & $\mathrm{c}_{\mathrm{T}}$ & $\varphi$ & $y_{x}$ & $L_{E}$ & $D_{1}$ & $D_{2}$ & $\theta$ & $F$ \\
\hline & $(\%)$ & $(--)$ & (m) & (m) & $(--)$ & $(--)$ & $(--)$ & $(--)$ \\
\hline $\mathrm{P} 1$ & 1.19 & 2.96 & 1.70 & 1.09 & 0.650 & 0.549 & 0.40 & 2000 \\
\hline $\mathrm{P} 2 \mathrm{a}$ & 2.00 & 2.84 & 1.71 & 1.10 & 0.653 & 0.582 & 0.29 & 894 \\
\hline $\mathrm{P} 2 \mathrm{~b}$ & 1.97 & 2.86 & 1.72 & 1.11 & 0.671 & 0.582 & 0.33 & 918 \\
\hline P3 & 2.86 & 2.79 & 1.68 & 1.07 & 0.690 & 0.607 & [a] & 515 \\
\hline P4 & 1.49 & 3.55 & [b] 1.85 & 0.94 & 0.640 & 0.583 & 0.21 & 1559 \\
\hline P5 & 2.47 & 3.94 & [b] 1.93 & 1.01 & 0.624 & 0.531 & 0.38 & 765 \\
\hline P6 & 2.16 & 5.45 & [b] 2.18 & 0.96 & 0.674 & 0.579 & 0.36 & 1102 \\
\hline L1 & 1.66 & 1.37 & [b] 0.93 & 0.32 & 0.603 & 0.590 & 0.05 & 824 \\
\hline L2 & 2.40 & 1.33 & [b] 0.89 & 0.28 & 0.623 & 0.607 & 0.05 & 464 \\
\hline Notes: & [a] & \multicolumn{3}{|c|}{$\Delta \mathrm{T}$ was not measured. } & & & & \\
\hline & [b] & \multicolumn{7}{|c|}{ Stratification not fully developed; $y_{x}$ estimated from point of inflection } \\
\hline
\end{tabular}




\subsection{Simplified Model}

We have previously presented [17] a simplified, one-dimensional, steady-state model of buoyancy-driven ventilation under isothermal conditions, leading to this vent-sizing equation:

$$
F \equiv \frac{A D}{S} \sqrt{2 g h}=\phi^{\frac{1}{2}}\left[\frac{1-c_{T}(1-\delta)+\left(1-c_{T}\right)^{2}}{(1-\delta) c_{T}{ }^{3}}\right]^{\frac{1}{2}}
$$

Figure 7 compares our experimental results (points are based on Table 2) to the simple model (curves and curve segments are based on Equation 2). The figure shows how the equation correctly tracks the relationship between the dimensionless vent size $(F)$, stratification factor $(\varphi)$, and concentration at the top vent $\left(\mathrm{c}_{\mathrm{T}}\right)$ over significant ranges of these variables. The range of stratification factors shown in Table 2 and Figure 7 is discussed in Section 5. For this comparison, we calculated values of the vent discharge coefficient (D) from the test data. First, we calculated the volumetric flow rate through the top vent, $\mathrm{Q}_{\mathrm{T}}$, based on the continuity equation for helium:

$$
\begin{aligned}
& Q_{T} c_{T}=S \\
& Q_{T}=S / c_{T}
\end{aligned}
$$

Then, based on continuity of both air and helium,

$$
Q_{B}=Q_{T}-S
$$

Then, as developed previously [17], we calculated:

$$
D=\left[\frac{\rho_{T} Q_{T}{ }^{2}+\rho_{o} Q_{B}{ }^{2}}{2 A^{2} g h\left(\rho_{o}-\rho_{\text {avg }}\right)}\right]^{\frac{1}{2}}
$$

This formulation assumes equal values of $\mathrm{D}$ for the top and bottom vents, and it assumes that the flow through the vents is driven only by the static pressure difference, rather than by momentum or other effects. The symbol $\mathrm{D}_{1}$ denotes the apparent value of $\mathrm{D}$ given by Equation 6 with experimental values of the densities based on helium concentration:

$$
\rho=\rho_{o}[1-c(1-\delta)]
$$

Because $\mathrm{D}_{1}$ is calculated using the assumptions of the simple model, the agreement between the simple model and the test data is exact when $\mathrm{D}_{1}$ is inserted into Equation 2, as shown in Figure 7. The validity of the simple model can then be evaluated by comparing values of $\mathrm{D}_{1}$ with established values of $\mathrm{D}$ for this type of vent. The values of $\mathrm{D}_{1}$ listed in Table 2 range from 0.603 to 0.690 . These numbers are somewhat higher than the reference value 0.60 , corresponding to a resistance coefficient reported by Idelchik [22] for an orifice in a thin wall with infinite surface 
area, which approximates our geometry. Possible reasons for the higher values in our experiment are momentum and thermal effects.

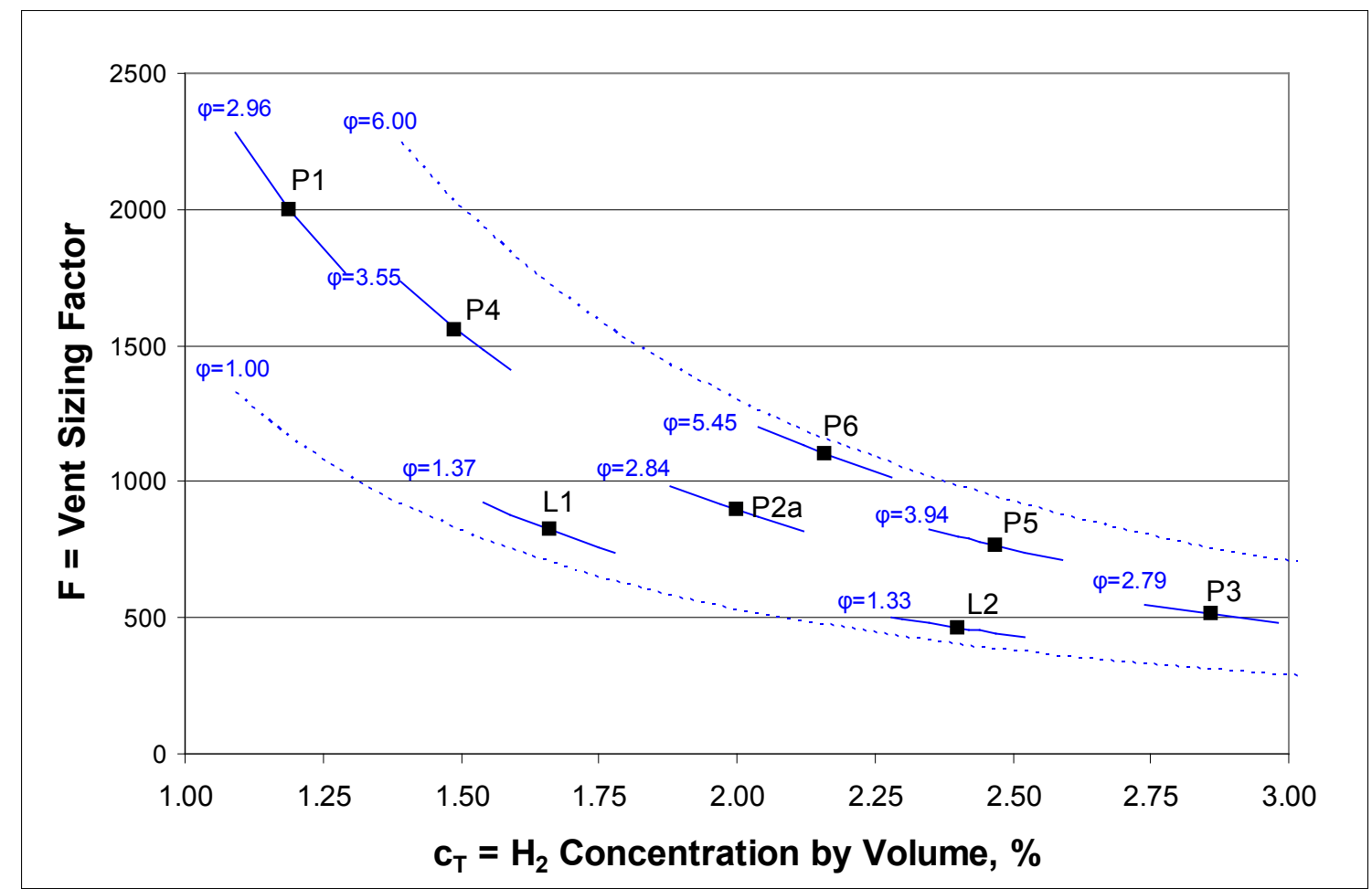

Figure 7. Comparison of simple model (curves and curve segments based on Eqn. 2) with experimental data (points from Table 2)

Momentum generated by the buoyant upward motion of the plume is deflected horizontally by the ceiling. The component of that momentum in the direction of the top vent may augment the buoyancy force in driving flow through the top vent. We designed a test to measure this effect. As shown in Figure 8, we installed a foam-board baffle to block the line-of-sight path from the top of the plume to the top vent. The baffle, hinged at the ceiling, is $91.4 \mathrm{~cm}$ wide, $62.2 \mathrm{~cm}$ high, and offset $1.09 \mathrm{~m}$ from the vent. In Case P2a, the baffle was removed from the flow path by taping it flat against the ceiling. Then, the tape was removed so the baffle deployed to the position shown in Figure 8. After waiting again for steady-state conditions, Case P2b was recorded. The values of $\mathrm{D}_{1}$ are nearly identical for the two cases (Table 2), ruling out significant momentum effects on vent flow, at least for this case. (The slight increase in $\mathrm{D}_{1}$ with the baffle deployed is attributed to the change in thermal conditions between the two measurements, as shown by $\Delta \mathrm{T}$ in Table 1.)

To compensate for thermal effects, we modified Equation 7 as follows ( $\mathrm{T}$ in $\mathrm{K}$ ):

$$
\rho=\rho_{o}[1-c(1-\delta)] \cdot\left[\frac{T_{o B}+T_{o T}}{T_{i B}+T_{i T}}\right]
$$

The values of $\mathrm{D}_{2}$ shown in Table 2 are based on Equation 6 with $\rho_{\text {avg }}$ calculated by Equation 8 . These values range from 0.531 to 0.607 . Although the four measurement points $(\mathrm{oB}, \mathrm{oT}$, $\mathrm{iB}$, and iT) only approximate the average temperatures over the vent height inside and outside the test room, this comparison indicates the sensitivity of $\mathrm{D}$ to the deviation from isothermal conditions 
in our tests. The differences between the experimental values of $\mathrm{D}$ and the literature reference value are of similar magnitude as the thermal effects.

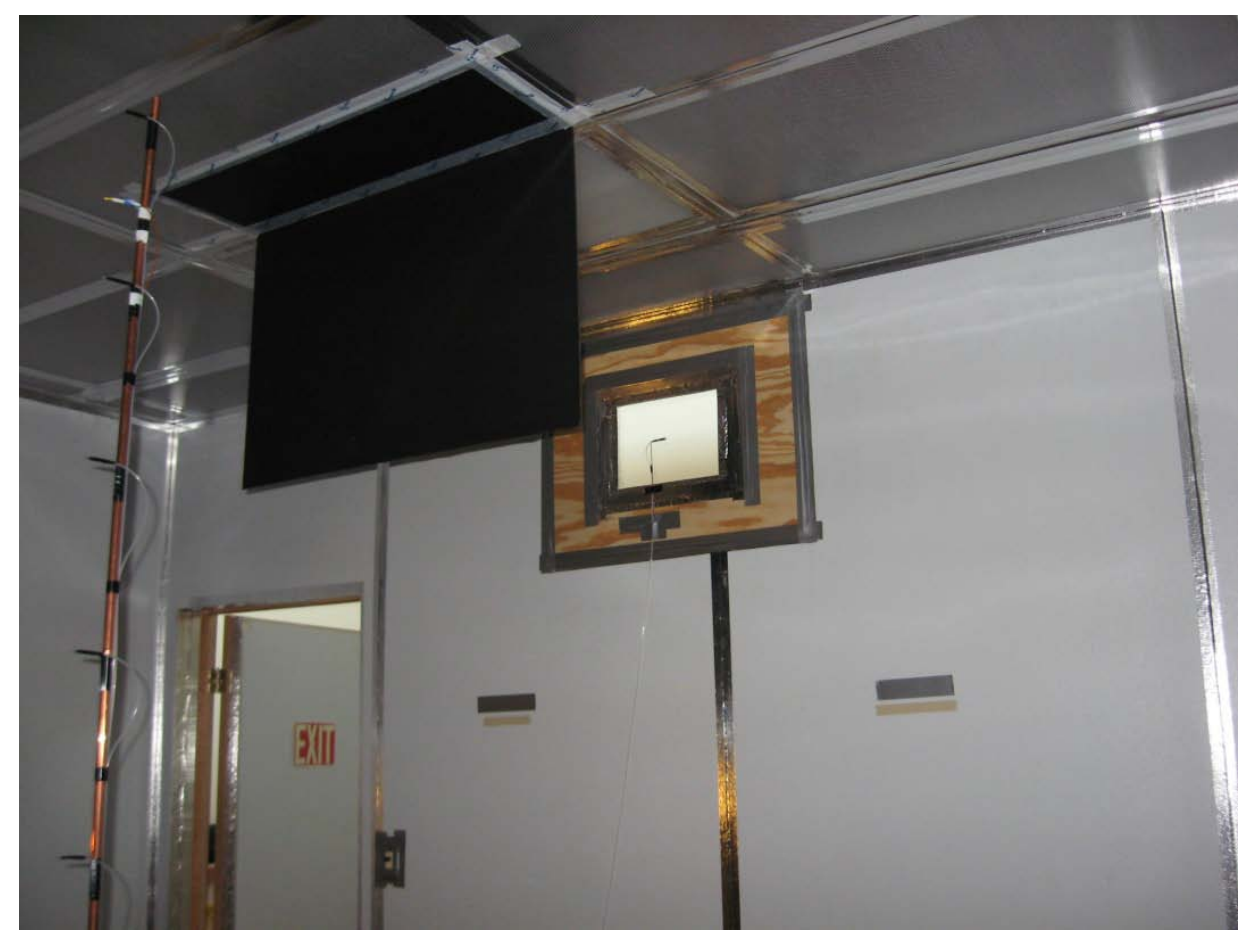

Figure 8. Vent baffle used to test momentum effect in Case P2b

The simple model is a good predictor of steady-state concentration under isothermal conditions. However, the stratification factor $\varphi$ must be determined by some other means (Section 5).

\subsection{Leakage Correction}

The rate at which helium escapes from the test room through vents or cracks depends on the concentration $\left(\mathrm{c}_{\mathrm{T}}\right)$ and stratification $(\varphi)$, as shown by Equation 2. In the leakage test (Section 3.2 ), both the concentration and stratification were different from those in the ventilation test cases, because (1) the concentration varied among the test cases and (2) the stratification depends on vent flow. To correct for leakage in the ventilation tests, we used the simple model to calculate the equivalent vent area of the cracks based on the leakage test results, the height between vents, and an assumed value of $\mathrm{D}=0.60$. From Equation 2:

$$
A_{\text {Leak }}=\frac{S}{D \sqrt{2 g h}} \phi^{\frac{1}{2}}\left[\frac{1-c_{T}(1-\delta)+\left(1-c_{T}\right)^{2}}{(1-\delta) c_{T}{ }^{3}}\right]^{\frac{1}{2}}
$$

Equation 9 yields $A_{\text {Leak }}=7.83 \mathrm{~cm}^{2}$. Based on the physical dimensions of the vents, the area of each open vent is $\mathrm{A}=791.7 \mathrm{~cm}^{2}$. To account for the leakage area, we adjusted the vent area using

$$
\mathrm{A}^{\prime}=\mathrm{A}+\mathrm{A}_{\text {Leak }}
$$

Thus, $A^{\prime}=791.7+7.8=800 \mathrm{~cm}^{2}$ or $0.0800 \mathrm{~m}^{2}$. We used this value of $A^{\prime}$ in our simple model calculations and in the CFD model. 


\subsection{Entrainment and Stratification}

Previous researchers have described the relationship between the entrainment of fluid into a plume and the resulting stratification pattern for buoyancy-driven displacement ventilation. Linden et al. [23] showed, through analysis and experiments with dyed liquid, a stratification pattern consisting of two rather uniform layers sharply divided by an interface plane. The plane occurs at the height at which the amount of fluid entrained in the plume is equal to the flow rate through the inlet vent; thus, all the mass transport across the plane is conveyed by the plume, and the vertical velocity through the remainder of the plane is zero. Lane-Serff et al. [24] presented a thorough description of buoyant plume geometry for cases in which "the density difference between the plume and the ambient fluid is relatively small," which is not the case here. Lowesmith et al. [25] numerically solved the coupled differential equations involving continuity of mass, momentum, and buoyancy in their model for leaking methane-hydrogen mixtures.

Our test results show three distinct layers in a fully developed stratification pattern (e.g. Case P3, Figure 9):

- The bottom layer with near-zero helium concentration

- The top layer with a rather uniform nonzero helium concentration

- The middle layer with a gradual transition between the helium concentrations below and above.

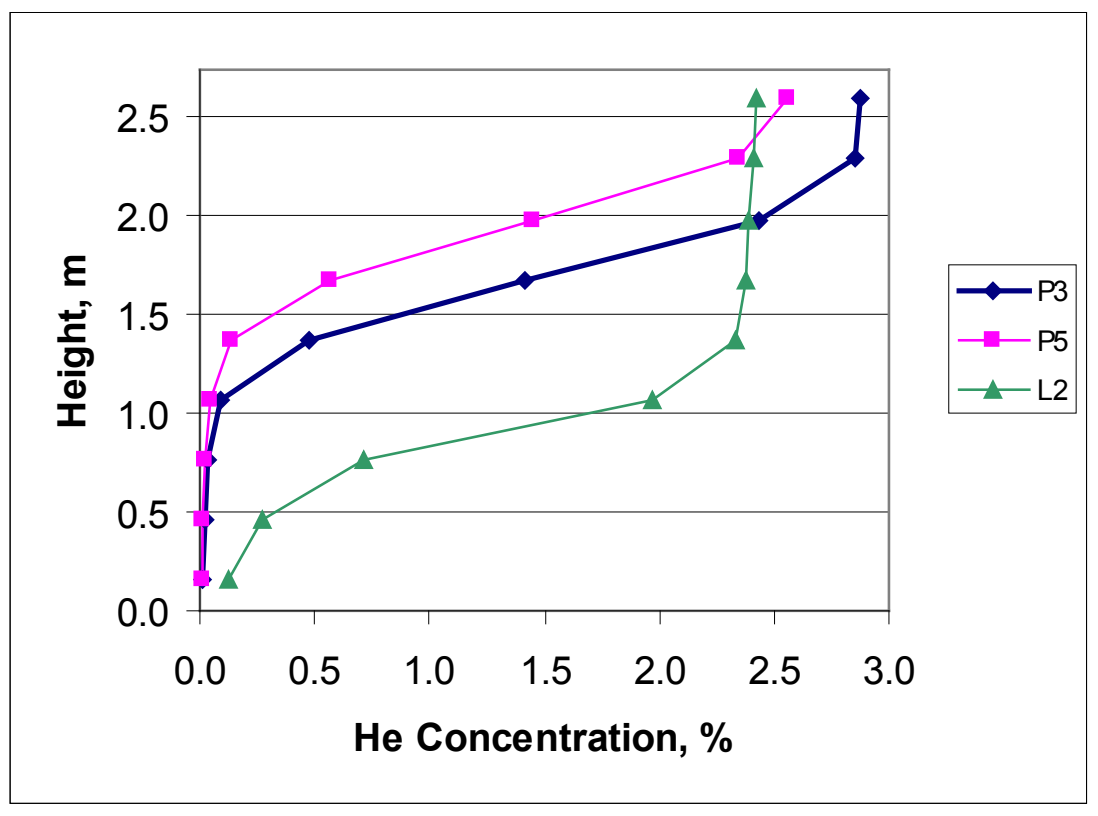

Figure 9. Stratification patterns for three test cases, from data in Table 1

Convective mixing and diffusion of helium across the interface plane are both significant causes of the transition layer (see Section 7). For analysis, we define the transition height $\left(\mathrm{y}_{\mathrm{x}}\right)$ as the location where the concentration of helium is halfway between the values in the top and bottom layers. In some of our test cases (e.g. Case P5, Figure 9), the transition layer terminates at the ceiling and the top layer does not occur. In Cases L1 and L2 (Figure 9), the transition layer terminates at the floor and the bottom layer does not occur. In these cases, we identify $\mathrm{y}_{\mathrm{x}}$ at the 
point of inflection in the stratification curve, based on the symmetry observed in the fully developed cases. We further define the entrainment length $\left(\mathrm{L}_{\mathrm{E}}\right)$ as the vertical distance between the injection diffuser (the leak) and the transition height. As shown in Table $2, \mathrm{~L}_{\mathrm{E}} \approx 1 \mathrm{~m}$ over a variety of test conditions with the point diffuser. With the line diffuser, $\mathrm{L}_{\mathrm{E}} \approx 0.3 \mathrm{~m}$. Thus, over the range of cases we tested, leak geometry is the primary variable affecting $\mathrm{L}_{\mathrm{E}}$. The combination of source height $\left(\mathrm{y}_{\mathrm{S}}\right)$ and entrainment length $\left(\mathrm{L}_{\mathrm{E}}\right)$ determines the transition height $\left(y_{x}\right)$. The stratification factor $(\varphi)$ depends on the positions of the vents within the stratification profile. 


\subsection{Experimental Error}

The sources of error in our measurements include:

- Tolerance on the $4 \%$ calibration gas sample: $\pm 0.04 \%$ helium

- Nonlinearity of gas analyzer between calibration points: $\pm 0.02 \%$ helium

- Factory calibration of mass flow valve used for helium injection: \pm 1 NLPM

- Humidity overcorrection. We corrected for the effect of humidity on the gas analyzer by subtracting the measurement at the inlet (bottom) vent from all the measurements (Section 2). At the highest measured helium concentration (3\% in the room leakage test), the humidity ratio was diluted to $97 \%$ of its air-only value. Thus, we overcorrected by $3 \%$ of humidity offset. The largest humidity offset in any of the test cases was $0.20 \%$ helium. Therefore, this error is no more than $0.006 \%$ helium.

- Leakage from the test room: 0.60 LPM under leak test conditions. We corrected for this leakage (Section 4.1), so the remaining error should be negligible compared to the flow valve error.

- Temperature control and measurement (see below).

- Nonsteady conditions during measurements (see below).

The largest source of error, with regard to model validation, is the deviation from isothermal conditions, along with the coarseness of our thermal measurements (only two measurement points inside the test room and two outside) and nonsteady thermal conditions. An estimate of the total error is reflected in the ranges of our derived values of $\mathrm{D}_{1}$ and $\mathrm{D}_{2}$ (Table 2):

- $\mathrm{D}_{1}$ ranges from 0.603 to 0.690 , average 0.648

- $\mathrm{D}_{2}$ ranges from 0.531 to 0.607 , average 0.579 , range 0.076 .

The difference of 0.069 between the $\mathrm{D}_{1}$ and $\mathrm{D}_{2}$ averages $(12 \%$ of 0.60$)$ indicates the approximate magnitude of thermal effects on vent flow and thus $\mathrm{c}_{\mathrm{T}}$ (per Equation 3). The range of 0.076 in the temperature-corrected values of $\mathrm{D}_{2}(0.57 \pm 7 \%)$ indicates the approximate magnitude of nonsteady effects and the coarse resolution of our temperature measurements. 


\subsection{Computational Fluid Dynamics Model Validation}

We have previously [17] developed a CFD model for the slow leak/natural ventilation scenario under study. We used the FLUENT version 6.3.26 CFD software [26], with an implicit, pressure-based solver and first order discretization of convection and time for speed and stability. We explored both the renormalization group (RNG) k- $\varepsilon$ turbulence model with the differential viscosity option enabled (see Section 12.19.5 in reference [27]) and the laminar model. The results indicated turbulence intensities lower than $1 \%$ in more than $85 \%$ of the domain in all the cases we ran. Other researchers have found that k- $\varepsilon$ turbulence models tend to overpredict mixing of gas released from slow leaks [13], thus underpredicting stratification, and the use of a laminar model leads to a more stratified hydrogen distribution [5]. Based on Equation 2 and Figure 7 (Section 4), higher stratification corresponds to higher hydrogen concentrations for a given vent size and leak rate. Thus, the laminar model is more conservative for safety engineering, and we used the laminar model for the ventilation study. The flow visualization test described in Section 3.1 supports the choice of the laminar model.

In our previous work, the model domain corresponded to the interior of the enclosure, with atmospheric pressure boundary conditions at the inlet and outlet vents. This configuration led to overprediction of flow through the vents, because the loss in total pressure on the outside of the vents was neglected. We modified our model by including a space outside the vents in the domain. The outside space is physically bounded by the floor and wall of the outer building (Figure 2), and analytically bounded by atmospheric pressure boundary conditions on the other surfaces. This model agreed very well with test results, as described below. The model determines static pressure differences caused by the hydrostatic head outside the domain, based on the specified ambient outdoor air density. We used the incompressible ideal gas option ${ }^{7}$ in FLUENT to determine density as a function of the air-hydrogen (or -helium) mixture within the domain. Time steps were changed during the simulation to speed convergence. Initially, the time step was 0.1 seconds to capture the transient behavior as the leak started. When the iterations to convergence at each time step dropped below 10, the time step was increased. The largest time step used was 0.4 to 0.5 seconds. ${ }^{8}$

We previously used a polyhedral ${ }^{9}$ mesh for computational economy. However, for improved resolution of flow through the vents, we used a tetrahedral mesh in the current study. We arranged the experiment and the model with bilateral symmetry, so the model domain for half the space represents each half. A sensitivity study showed that the solution is insensitive to grid density at about 150,000 to 200,000 cells, over the $72.2 \mathrm{~m}^{3}$ domain $\left(41.3 \mathrm{~m}^{3}\right.$ inside the test room and $31.0 \mathrm{~m}^{3}$ outside). The computations reported in this article were performed with 205,215 cells. Thus, the average size of a grid cell was $0.35 \mathrm{~L}\left(350 \mathrm{~cm}^{3}\right)$, with a higher cell density near the leak and the vents where gradients are high, and a lower cell density where gradients are lower. Because we were studying steady-state conditions, we could reduce computation time by

\footnotetext{
${ }^{7}$ With the incompressible ideal gas option, operating pressure only is used in the density calculation, and this is suitable for low Mach number flows. Density would be calculated as a function of operating pressure and local relative pressure in a compressible, high Mach number flow. See Section 8.3.5 in reference [27].

8 The Courant number was not monitored during the simulations, because the stability of the implicit solution method does not rely on this indicator, as would an explicit solution method. In retrospect, the value of the Courant number was typically 0.2 .

${ }^{9}$ The FLUENT software generates a mesh consisting of polyhedra with a variable number of faces.
} 
using the final conditions from one computation as the initial conditions for the next one, decreasing the process time to steady state. With this approach and the indicated mesh density, the computation time was typically 24 to 48 hours per case on a Dell Precision 670 dualprocessor computer with $8 \mathrm{~GB}$ of memory, running the Red Hat Enterprise Linux operating system. However, some cases required up to a week for the model to reach a stable steady-state solution.

For model validation, we selected the point diffuser test case that came closest to isothermal conditions, based on the smallest value of $\theta$-Case P4. We modeled the atmospheric pressure measured at the test room under assumed isothermal conditions. Figure 10 shows a mole fraction contour map of the steady-state solution. Figure 11 shows a comparison of the measured and modeled stratification profiles at the measurement points. In the laboratory, steady conditions were observed after about 190 minutes. The CFD model reached steady state in less time ${ }^{10}$ but was continued for 355 minutes to verify the steady solution. Although we did not record the transient response of concentration versus time with the CFD model, the behavior was similar to that shown in our previous paper (see Figure 4 in reference 17). Concentration increased monotonically, with no significant oscillation. The shapes of the profiles in Figure 11 agree very well, although the modeled profile is offset about $20 \mathrm{~cm}$ below the measured profile. The difference in concentration is $0.03 \%$ helium near the floor and $0.05 \%$ helium near the ceiling. This is very good agreement for safety engineering. The differences in concentration are in the direction of thermal effects that occurred in the laboratory. ${ }^{11}$ The value of D corresponding to the CFD result is 0.527 , about $10 \%$ lower than the value of $\mathrm{D}_{2}$ for the test case.

Because our laboratory is located 1,800 $\mathrm{m}$ above sea level in Golden, Colorado, we studied the sensitivity of the CFD result to elevation. We adjusted the ADR from 1.000 at sea level to 0.804 in Golden and the diffusion coefficient for helium in air from $0.733 \mathrm{~cm}^{2} / \mathrm{s}$ at sea level to 0.905 $\mathrm{cm}^{2} / \mathrm{s}$ in Golden, based approximately on inverse proportion with respect to pressure. As shown in Figure 12, there is negligible sensitivity of the result to elevation. ${ }^{12}$ Because this result surprised us, we ran an additional comparison with the diffusion coefficient set to 0 . This result, also shown in Figure 12, indicates a narrower transition layer. We interpret this result to mean that the transition layer is caused by both convective mixing and diffusion of helium across the interface plane. (See also discussion in Section 5.)

Figure 13 shows a comparison of the CFD result with hydrogen versus helium as the leaking gas. This difference is important because models are typically validated against experimental results using helium and then adjusted for hydrogen to assess the risk in hydrogen leakage scenarios. Our results show a hydrogen concentration higher than the helium concentration by a difference of $0.2 \%$ near the ceiling. In a similar CFD comparison, Swain et al. [7] found that helium and hydrogen concentrations were very nearly equal near the ceiling, although the test conditions were different than ours in those cases. Possible causes of this difference include physical phenomena (such as the higher velocity in the hydrogen plume) and CFD modeling issues.

\footnotetext{
${ }^{10}$ Thermal transients extended the time to steady state in the lab but were not an issue in the isothermal CFD model.

${ }^{11}$ With $\Delta \mathrm{T}>0$, as shown in Table 1 , thermal buoyancy augments helium buoyancy in driving vent flow, thus decreasing the steady-state concentrations. The CFD model, which is based on assumed isothermal conditions, is not influenced in this manner.

${ }^{12}$ The CFD computations compared in Figure 12 used the same volumetric leakage rate (12.3 LPM), not the same mass leakage rate.
} 


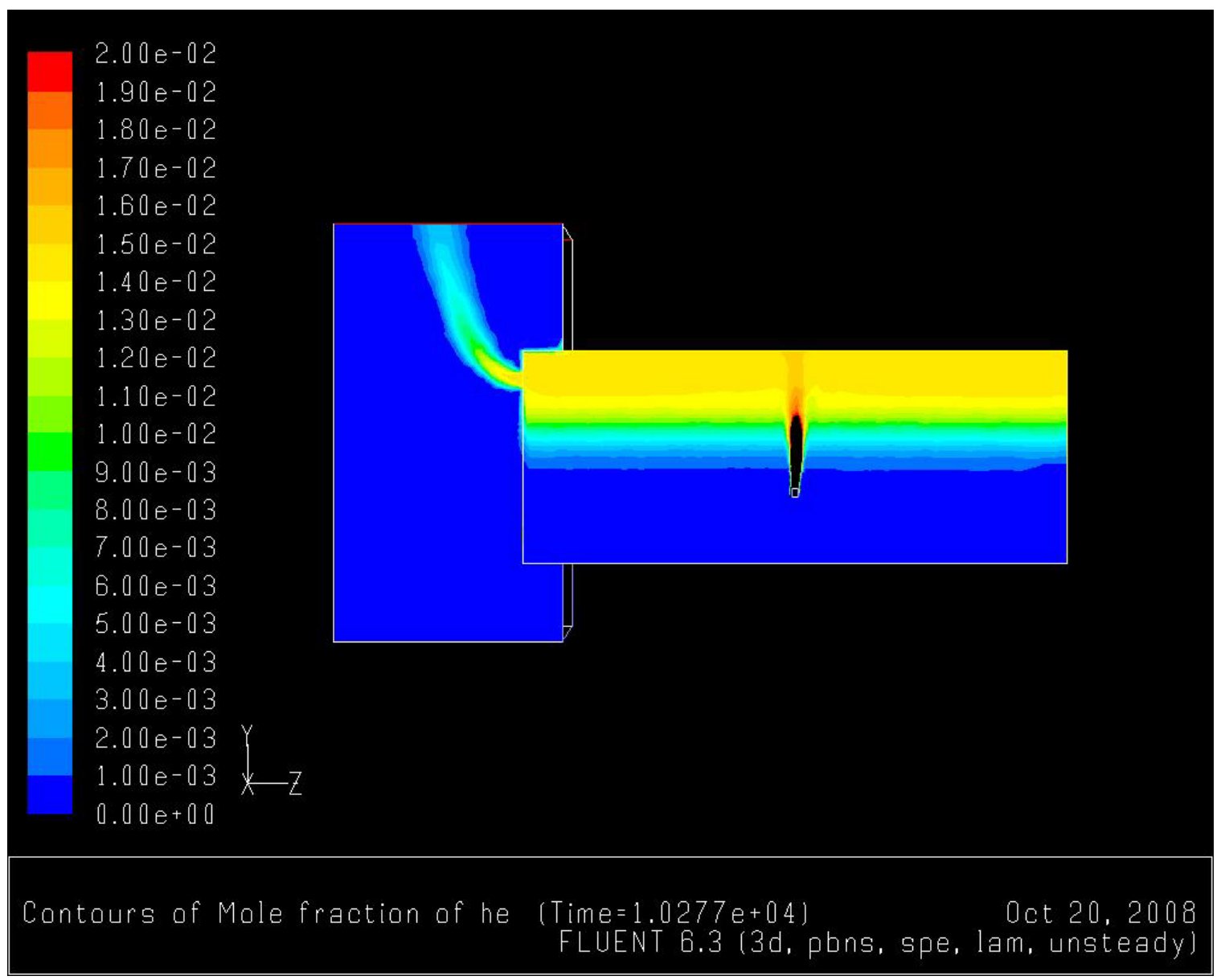

Figure 10. Graphic result of CFD model for Case P4. Cross section of test room, through vents, is shown. Color scale is helium mole fraction; the full-scale value of 0.02 corresponds to $2 \%$ helium by volume. Elapsed time is 171 minutes (steady state). 


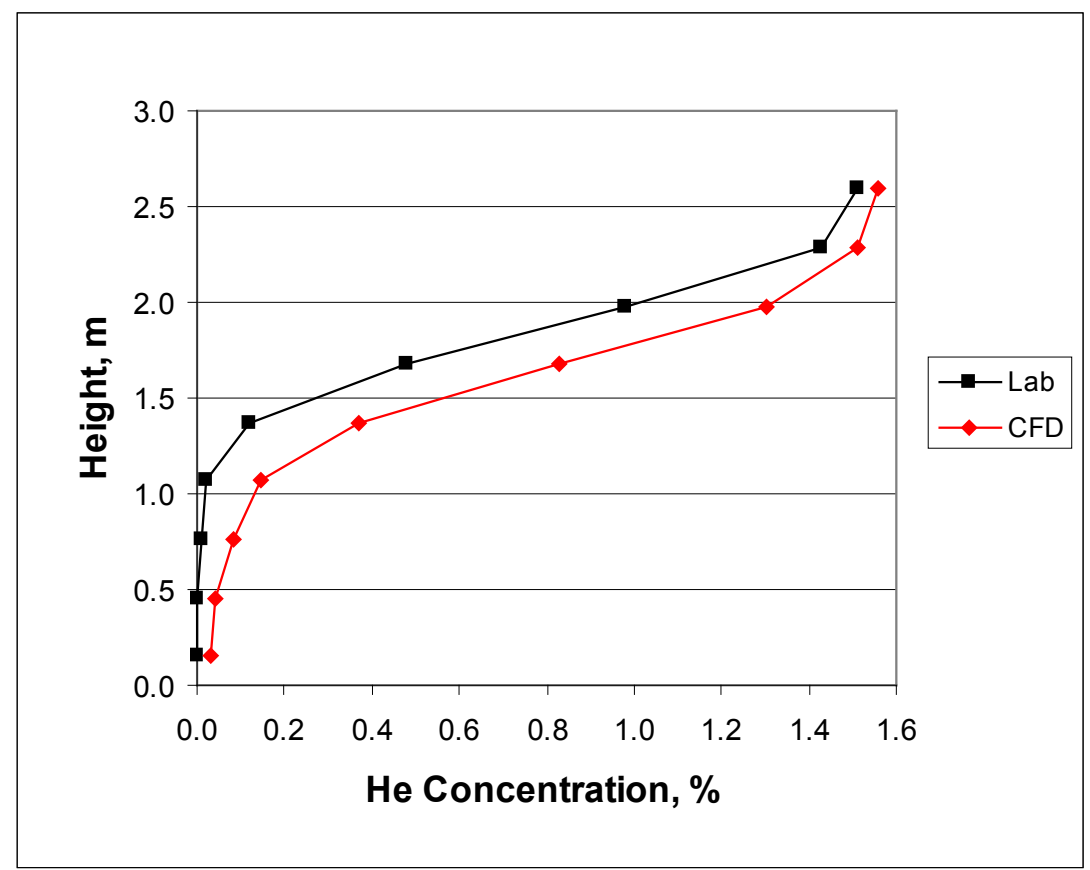

Figure 11. Comparison of CFD result with test result for Case P4

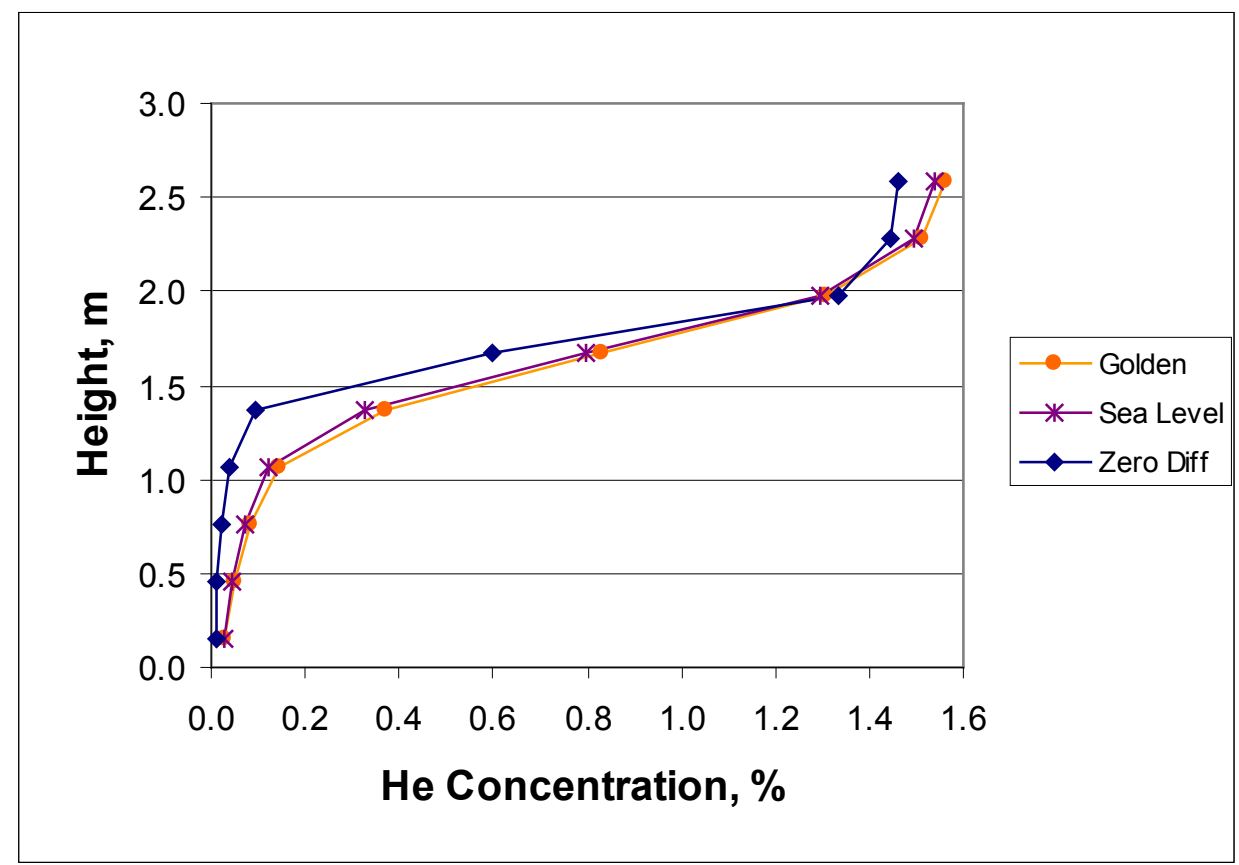

Figure 12. Sensitivity of CFD result to elevation above sea level and diffusion coefficient 


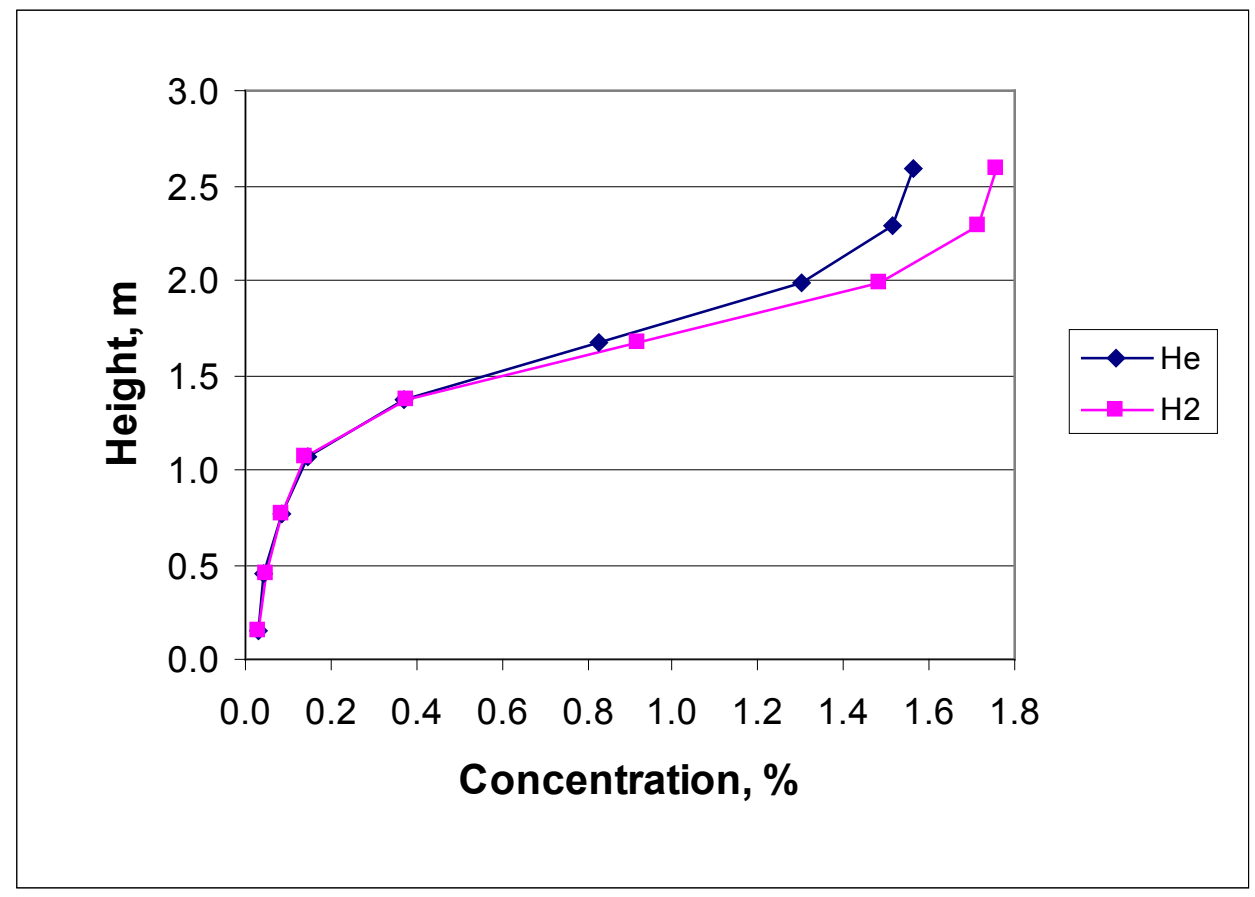

Figure 13. Comparison of CFD results for helium and hydrogen 


\subsection{Conclusions}

We have generated a set of experimental data, summarized in Tables 1 and 2, with sufficient documentation that others can use it to validate models of buoyancy-driven ventilation in the slow, low-velocity leak scenario under isothermal conditions with no wind effects.

The test results confirm our simple model formulation, which indicates parametric relationships among the design variables. The agreement is indicated by (1) experimental values of $D$ that agree well with the literature reference value for similar geometry, and (2) exact agreement of the model with test results when these values of D are applied (Figure 7).

The measured stratification factors $(\varphi)$ range from 1.33 to 5.45 (Table 2). The lower limit is 1.00; however, there is no theoretical upper limit. $\varphi$ depends on the leak height above the floor, the leak geometry, the height of the enclosure, and the locations of the vents within the stratification profile. Specific leak scenarios likely to be encountered in practice are needed to determine a realistic range for $\varphi$.

Comparisons of CFD model results with test results led to an improvement of our CFD model, in which the atmospheric pressure boundary condition was moved away from the vents, outside the enclosure. The improved model agrees well with test results (Figure 11). We have described our modeling approach in sufficient detail that others can use it.

A significant uncertainty in applying our findings is the range of leakage rates that will occur with hydrogen vehicles. Our models can predict hydrogen concentrations for given leakage scenarios. However, further research is needed to ascertain the occurrence probabilities of various leakage scenarios before this research can be applied to safety engineering for buildings.

Temperature differences between the inside and outside of the enclosure where leakage occurs can have a significant effect on the indoor hydrogen concentration. Thermocirculation may either augment or oppose ventilation driven by hydrogen buoyancy. In the laboratory, a $\Delta \mathrm{T}$ as small as $0.3 \mathrm{~K}$ is equivalent to about $0.1 \%$ concentration, which is a measurement concern. In garages, a $\Delta \mathrm{T}$ of $3 \mathrm{~K}$ is equivalent to about $1 \%$ concentration, which is a safety engineering concern. This effect can occur in nearly any climate because of steady-state or transient temperature differences between the garage and the ambient air, in either hot or cold weather. Further research is needed to evaluate the ranges of architectural and weather conditions under which this effect is dangerous. 


\subsection{References}

1. Bain, A.; Barclay, J.A.; Bose, T.K.; Edeskuty, F.J.; Fairlie, M.J.; Hansel, J.G.; Hay, D.R.; Swain, M.R.; Ohi, J.M.; Gregoire Padró, C.E. (1998). Sourcebook for Hydrogen Applications, TISEC, Inc., Montreal, Canada.

2. International Code Council. International Fire Code, Section 2211.7.1.1, 2006, Washington, D.C. www.iccsafe.org, last viewed 5 June 2007.

3. National Fire Protection Association. Vehicular Fuel Systems Code, Section 9.3.3.5.4.1, 2006, Quincy, MA. www.nfpa.org, last viewed 12 June 2007.

4. Swain, M.R.; Swain, M.N. (1996). "Passive Ventilation Systems for the Safe Use of Hydrogen." International Journal of Hydrogen Energy 21:823-835.

5. Breitung, W.; Necker, G.; Kaup, B.; Veser, A. (2001). "Numerical Simulation if Hydrogen Release in a Private Garage." Proceedings of Hypothesis IV, 9-14 September 2001, Strahlsund, Germany, p. 368.

6. Venetsanos, A.G.; Papanikolaou, E.; Delichatsios, M.; Garcia, J.; Hansen, O.R.; Heitsch, M.; Huser, A.; Jahn, W.; Jordan, T.; Lacome, J.-M.; Ledin, H.S.; Makarov, D.; Middha, P.; Studer, E.; Tchouvelev, A.V.; Teodorczyk, A.; Verbecke, F.; Van der Voort, M.M. (2009). "An Inter-Comparison Exercise on the Capabilities of CFD Models To Predict the Short and Long Term Distribution and Mixing of Hydrogen in a Garage." International Journal of Hydrogen Energy, accepted.

7. Swain, M.R.; Filoso, P.; Grilliot, E.S.; Swain, M.N. (2003). "Hydrogen Leakage Into Simple Geometric Enclosures. International Journal of Hydrogen Energy 28:229-248.

8. Swain, M.R.; Filoso, E.S.; Swain, M.N. (2005). "Ignition of Lean Hydrogen-Air Mixtures." International Journal of Hydrogen Energy 30:1447-1455.

9. Swain, M.R.; Filoso, E.S.; Swain, M.N. (2007). “An Experimental Investigation Into The Ignition of Leaking Hydrogen" International Journal of Hydrogen Energy 32:287-295.

10. Swain, M.R. (2001). "Fuel Leak Simulation." Proceedings of U.S. DOE Hydrogen Program Review, Baltimore, MD, 17-19 April 2001, pp. 679-689. NREL Report No. CP-610-30535, www.nrel.gov/docs/fy01osti/30535.pdf.

11. CRC Handbook of Chemistry and Physics. (2007). $87^{\text {th }}$ edition, Boca Raton, FL: CRC Press.

12. Gupta, S.; Brinster, J.; Studer, E.; Tkatschenko, I. (2007). "Hydrogen Related Risks Within a Private Garage: Concentration Measurements in a Realistic Full Scale Experimental Facility." Proceedings of the 2nd International Conference on Hydrogen Safety, 11-13 September 2007, San Sebastian, Spain. 
13. Papanikolaou, E.A.; Venetsanos, A.G. (2005). "CFD Modeling for Helium Releases in a Private Garage Without Forced Ventilation. Proceedings of First International Conference on Hydrogen Safety, 8-10 September 2005, Pisa, Italy. conference.ing.unipi.it/ichs2005/index.html, last viewed 27 April 2007.

14. Wilkening, H.; Baraldi, D. (2007). "CFD Modelling of Accidental Hydrogen Release From Pipelines.” International Journal of Hydrogen Energy 32:2206-2215.

15. Venetsanos, A.G.; Bartzis, J.G. (2007). "CFD Modeling of Large-Scale LH2 Spills in Open Environment.” International Journal of Hydrogen Energy 32:2171-2177.

16. Schmidt, D.; Krause, U.; Schmidtchen, U. (1999). "Numerical Simulation of Hydrogen Gas Releases Between Buildings. International Journal of Hydrogen Energy 24:479-488.

17. Barley, C.D.; Gawlik, K.; Ohi, J.; Hewett, R. (2007). “Analysis of Buoyancy-Driven Ventilation of Hydrogen From Buildings." Proceedings of the $2^{\text {nd }}$ International Conference on Hydrogen Safety, 11-13 September 2007, San Sebastian, Spain. NREL Report No. CP-550-41081, www.nrel.gov/docs/fy07osti/41081.pdf.

18. Schefer, R.W.; Houf, W.G.; San Marchi, C.; Chernicoff, W.P.; Englom, L. (2006). "Characterization of Leaks From Compressed Hydrogen Dispensing Systems and Related Components." International Journal of Hydrogen Energy 31:1247-1260.

19. Standard SAE J2578. (2008). Surface Vehicle Recommended Practice, Revised Proposed Draft, SAE International, Warrendale, PA. www.sae.org/servlets/index, last viewed 17 December 2008.

20. Parsons Brinkerhoff. (2004). Support Facilities for Hydrogen-Fueled Vehicles: Conceptual Design and Cost Analysis Study. West Sacramento, CA: California Fuel Cell Partnership. www.fuelcellpartnership.org/pdf/ResourceDocs/FacilitiesStudy08.2004.pdf.

21. American Society of Heating, Refrigerating and Air-Conditioning Engineers. (2005). Handbook-Fundamentals, Chapter 6, Eqn. 3, Atlanta, GA.

22. Idelchik, I.E. (1986). Handbook of Hydraulic Resistance, $2^{\text {nd }}$ ed., Diagram 4-18. New York: Hemisphere Publishing Corp.

23. P.F. Linden, G.F. Lane-Serff, D.A. Smeed, Emptying filling boxes: the fluid mechanics of natural ventilation, J. Fluid Mechanics 212 (1990) 309-335.

24. G.F. Lane-Serff, P.F. Linden, M. Hillel M, Forced, angled plumes, J. Hazardous Materials 33 (1993) 75-99.

25. B.J. Lowesmith, G. Hankinson, C. Spataru, M. Stobbart, Gas build-up in a domestic property following releases of methane/hydrogen mixtures, Proceedings of the $2^{\text {nd }}$ International Conference on Hydrogen Safety, San Sebastian, Spain, 11-13 September 2007.

conference.ing.unipi.it/ichs/fileadmin/user_upload/CD/PAPERS/12SEPT/1.1.62.pdf. 
26. FLUENT, Inc. www.fluent.com, last viewed 26 April 2007.

27. FLUENT 6.3 User's Guide, www.ipt.ntnu.no/manuals/Fluent.Inc/fluent6.3.26/help/index.htm, last viewed 2 April 2009. 


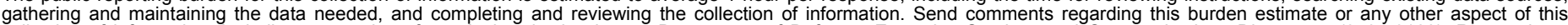

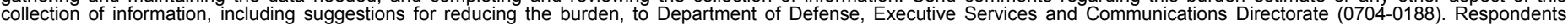

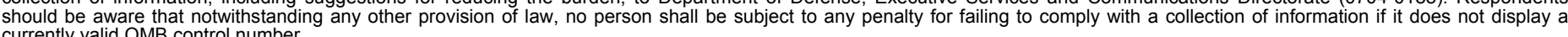

PLEASE DO NOT RETURN YOUR FORM TO THE ABOVE ORGANIZATION.

\section{REPORT DATE (DD-MM-YYYY) May 2009 \\ 2. REPORT TYPE \\ Technical Report}

4. TITLE AND SUBTITLE

Buoyancy-Driven Ventilation of Hydrogen from Buildings: Laboratory Test and Model Validation
3. DATES COVERED (From - To) 5a. CONTRACT NUMBER

DE-AC36-08-GO28308

5b. GRANT NUMBER
6. AUTHOR(S)

C.D. Barley and K. Gawlik 5d. PROJECT NUMBER

NREL/TP-550-45804

5e. TASK NUMBER

$\mathrm{H} 2747110$

5f. WORK UNIT NUMBER
7. PERFORMING ORGANIZATION NAME(S) AND ADDRESS(ES)

National Renewable Energy Laboratory

1617 Cole Blvd.

Golden, CO 80401-3393
8. PERFORMING ORGANIZATION REPORT NUMBER

NREL/TP-550-45804

9. SPONSORING/MONITORING AGENCY NAME(S) AND ADDRESS(ES)

10. SPONSOR/MONITOR'S ACRONYM(S) NREL

11. SPONSORING/MONITORING AGENCY REPORT NUMBER

12. DISTRIBUTION AVAILABILITY STATEMENT

National Technical Information Service

U.S. Department of Commerce

5285 Port Royal Road

Springfield, VA 22161

\section{SUPPLEMENTARY NOTES}

\section{ABSTRACT (Maximum 200 Words)}

Hydrogen gas leaking from a hydrogen-powered vehicle in a residential garage may form a flammable mixture with air. Passive, buoyancy-driven ventilation is one approach to limiting the concentration to a safe level. We explored the relationship between leak rate, ventilation design, and hydrogen concentration through laboratory testing, an algebraic analysis, and CFD modeling. We used helium to test slow, steady, low-velocity leaks in a full-scale test room under nearly isothermal, steady conditions, and we report the results in sufficient detail that other modelers can use them. The results show the importance and variability of stratification. Our algebraic and CFD models agree very well with the experimental results. We describe our CFD approach in sufficient detail for use by others. We tested under nearly isothermal conditions, but also discuss indoor-outdoor temperature difference as an important risk factor. Information about realistic leakage scenarios is needed to apply these results as safety recommendations.

\section{SUBJECT TERMS}

hydrogen; buoyancy; ventilation; cfd; computational fluid dynamics

\begin{tabular}{|c|c|c|}
\hline $\begin{array}{l}\text { a. REPORT } \\
\text { Unclassified }\end{array}$ & $\begin{array}{l}\text { b. ABSTRACT } \\
\text { Unclassified }\end{array}$ & $\begin{array}{l}\text { c. THIS PAGE } \\
\text { Unclassified }\end{array}$ \\
\hline
\end{tabular}

\begin{tabular}{|c|c|}
\hline $\begin{array}{l}\text { 17. LIMITATION } \\
\text { OF ABSTRACT }\end{array}$ & $\begin{array}{l}\text { 18. } \\
\text { OFUMBER } \\
\text { OFAGES }\end{array}$ \\
\hline UL & \\
\hline
\end{tabular}

19a. NAME OF RESPONSIBLE PERSON

19b. TELEPHONE NUMBER (Include area code) 